AperTO - Archivio Istituzionale Open Access dell'Università di Torino

Immigrant networks and remittances: Cheaper together?

This is a pre print version of the following article:

Original Citation:

Availability:

This version is available http://hdl.handle.net/2318/1684966

since 2021-12-17T15:07:17Z

Published version:

DOI:10.1016/j.worlddev.2018.07.008

Terms of use:

Open Access

Anyone can freely access the full text of works made available as "Open Access". Works made available under a Creative Commons license can be used according to the terms and conditions of said license. Use of all other works requires consent of the right holder (author or publisher) if not exempted from copyright protection by the applicable law. 


\title{
Immigrant Networks and Remittances: Cheaper together?*
}

\author{
Ainhoa Aparicio Fenoll ${ }^{\dagger}$ \\ Zoë Kuehn
}

This version: June 2017

\begin{abstract}
We estimate the causal effects of immigrant networks on individuals' remittance sending behavior for migrants from many different countries residing in Spain. Our methodology addresses typical issues that arise when estimating network effects: reverse causality, common unobserved factors, and self-selection. In particular, we instrument the size of networks by predicting the number of migrants in each location using the location's accessibility by distinct methods of transportation and information about how migrants from each country initially arrived in Spain. Our findings show that immigrants from above-average remitting countries remit more if they live in larger networks. Testing for mechanisms of network effects, we find that these migrants are more likely to send remittances via bank transfers which suggests that large networks of individuals who remit a lot might be better at sharing information about cheaper remittance channels (bank transfers compared to money orders in post offices or agencies). In line with this hypothesis we find that due to network effects migrants shy away from the most expensive remittance channels, potentially freeing resources for additional remittances. Our results suggest that network effects could boost policy efforts to lower remittance prices.
\end{abstract}

JEL classification: F24, J61, F22, O15, A14

Keywords: immigrant networks, remittances, migration, Spain

*We would like to thank José Ignacio García Pérez, Libertad González, Erzo Luttmer, Julián Messina, Núria Rodríguez Planas, Kurt Schmidheiny, Thijs Van Rens, Albrecht Glitz, Giovanni Mastrobuoni, and Ignacio Monzón, and participants at the Spanish Economic Simposium 2011, the MILLS workshop 2013, and the EALE conference 2016 for their helpful comments and suggestions. Zoe Kuehn acknowledges financial support from the Ministerio de Economia y Competitividad (ECO2013-44920-P) in Spain.

†ainhoa.aparicio@carloalberto.org · Collegio Carlo Alberto·Via Real Collegio $30 \cdot$ Moncalieri (TO) 10024 Italy · and IZA (Institute for the Study of Labor) · Bonn · Germany.

‡zoe.kuehn@uam.es · Universidad Autónoma de Madrid. Departamento de Análisis Económico: Teoría Económica e Historia Económica · Campus de Cantoblanco · 28049 Madrid · Spain. 


\section{Introduction}

Immigrants from the same country of origin tend to reside geographically close to each other. These so-formed networks seem to explain to an important extent why migrants from the same background who live in the same city or neighborhood make similar decisions, for instance regarding occupations (Patel and Vella [2013]) or human capital accumulation (Borjas [1995]). One important migrant-specific decision that moves billions of dollars around the globe each year is how much remittances to send. ${ }^{1}$ There are three direct reasons why individuals living surrounded by others from the same country of origin could make similar remittance choices: (i) Migrant communities can help to maintain ties with the home country thus increasing individuals' desire to remit, (ii) migrant communities can help to establish ties with the host country thus decreasing the desire to remit, and (iii) living surrounded by many co-nationals, in particular if they remit much, might provide for better information about cost effective ways of sending money home. ${ }^{2}$

The current paper estimates the causal effects of immigrant networks on individuals' remittance sending behavior and finds them to be positive and significant. Our data come from the Spanish Migrant Survey 2007, a unique database that includes detailed information about remittances sent and migrants' place of residence. Among developed countries, Spain experienced relatively late one of the most sudden migrant inflows. Between 1998 and 2007, Spain - a country of 45 million (2007) - welcomed more than 5 million immigrants from all five continents, and it became the fifth country in the world in terms of remittance outflows (see Figure A-1 of the Appendix). ${ }^{3}$

Our findings show that immigrants from above-average remitting countries remit more if they live in larger networks. We test for various mechanisms of network effects but find no evidence that they significantly alter migrants' labor market outcomes (employment, wages) nor that they affect return intentions or the desire for family reunifications. We do however find evidence for an information-sharing mechanism. Migrants from aboveaverage remitting countries who live in larger networks are more likely to use bank transfers for sending remittances compared to migrants from other countries or those living in smaller networks. This suggests that large networks of individuals who remit a lot might

\footnotetext{
${ }^{1}$ According to the World Bank, in 2015 remittance inflows to developing countries reached $\$ 435$ billion, equivalent to approximately $7 \%$ of output produced by low and middle income countries.

${ }^{2}$ There are also indirect ways in which migrant networks could affect remittances sent, as a byproduct of network effects on employment or wages.

${ }^{3}$ In 2007, Spain recorded remittance outflows of $\$ 14$ billion and was ranked 5 th after the US, Russia, Saudi Arabia, and Germany. Spain's remittance outflows in 2007 were equal to $5 \%$ of all remittance outflows worldwide, while Spanish GDP amounted to 2.5\% of World GDP (World Bank).
} 
be better at sharing information about cheaper remittance channels (bank transfers compared to money orders in post offices or agencies). Such cost savings could explain why when living in larger networks, migrants remit more. In line with this hypothesis, for a subset of important remittance receiving countries for which data is available (so called corridor countries), we find that due to network effects migrants shy away from the most expensive remittance channel for their country. Our results hence show that network effects could boost policy efforts by the World Bank to lower remittance prices ("Project Greenback"). ${ }^{4}$

Our methodology addresses the following issues that arise when estimating network effects: (i) Reverse causality: when trying to test how any group average affects an individual's behavior, the individual's behavior simultaneously affects the group average. Following Borjas [1995] we define remittance behavior at the country of origin level such that an individual's actions have no effect on the group average. (ii) Common unobserved factors: if negative income shocks in some destination countries or better economic conditions in certain locations cause individuals in the same network to remit more, independently of network effects. For instance, Mohapatra, Joseph, and Ratha [2009], Clarke and Wallsten [2003] or Yang and Choi [2007] provide evidence on increased remittance flows after natural disasters and weather shocks in migrants' countries of origin. Our regressions include a full set of country and location dummies which address the potential influence of common unobserved factors. (iii) Self-selection: the same unobservable individual characteristics that lead individuals to live close to their peers might also be driving their other decisions (Borjas [1998]). To address the issue of self-selection we instrument the size of networks following Gonzalez and Ortega [2012]. In particular, our instrument predicts the number of migrants residing in each location by combining information on how migrants from each country initially entered Spain with each location's accessibility by different means of transportation.

To the best of our knowledge, the existing literature on the effects of migrant networks on remittances considers only endogenously-formed social networks and focuses on specific migrant groups. For instance for the case of Mexican migrants in the US, AmuedoDorantes and Pozo [2006] find that larger social networks of more friends in the city of

\footnotetext{
${ }^{4}$ In 2011, the World Bank launched "Project Greenback," with the objective of reducing the average cost of sending remittances in order to increase remittances. The project envisioned a 5 percentage points decrease in costs over 5 years (estimated cost savings of $\$ 16$ million per year). As key challenges the project identified access to information and healthy competition amongst providers. Financial education workshops and organized awareness raising initiatives in selected cities (up to this date in Turin, Italy and Montreuil, France ) as well as monitoring of remittance prices (htps://remittanceprices.worldbank. org) were launched to achieve this objective.
} 
destination reduce income risk and hence remittances sent. Maggard [2004] differentiates between four types of networks formed by friends, family, other-ethnicity-based networks in the country of destination, and community networks in the country of origin and finds the first (last) type of network to have positive (negative) effects on remittances sent. The study by Chort, Gubert, and Senne [2012] considers Senegalese migrants in France and Italy and defines networks as a combination of relationships, family members in countries of destination, and migrants' participation in home-country associations. The authors find that network effects on remittances are only present when controlling for the value individuals assign to these networks. None of these studies addresses the before-mentioned problem of self-selection, and given that all consider rather specific groups of immigrants it is unclear if and how these results extent to migrants from other countries of origin.

Our study is also related to two other strands of literature on: (i) the effect of immigrant networks on other outcomes and (ii) other determinants of remittance sending behavior besides networks. Regarding the former, many studies attempt to address the typical challenges of estimating network effects. The before-mentioned paper by Borjas [1995] finds that intergenerational transmission of human capital depends to a large degree on the average human capital of an individual's ethnicity and that part of this effect is explained for by geographical proximity to others of the same ethnicity. In his paper the author addresses the problem of reverse causality by using national averages for human capital by ethnicity. By using neighborhood fixed effects he deals with the issue of locations' unobserved factors. However, self-selection and unobserved factors of ethnicities remain unaddressed. A couple of subsequent studies have used exogenous variation brought about by refugee placement policies to deal with self-selection; see for instance Aslund and Fredriksson [2009] for network effects on welfare use in Sweden, Damm [2009] for effects on migrants' wages in Denmark, and Beaman [2012] for non-monotonic network effects on migrants' labor market outcomes in the US. The paper by Munshi [2003] proposes an alternative approach. Instrumenting the number of individuals in the migrant network by past rainfall in the origin community, the author finds that Mexicans within larger networks are more likely to be employed and to have higher paying jobs.

However, none of the above-mentioned methods is applicable to our question because remittances are sent by all types of immigrants (including but not restricted to refugees) from very different countries of origin (including but not restricted to countries with high employment shares in agriculture). More generally applicable methods are those proposed in Bertrand, Luttmer and Mullainathan [2000] and in the before-mentioned paper by Patel and Vella [2013]. The latter define networks in Metropolitan Statistical Areas (MSAs) by country of origin and occupation, and they instrument networks by historical networks ten years ago. Bertrand, Luttmer and Mullainathan [2000] postulate that net- 
work effects are present if individuals replicate the behavior of their group when living surrounded by many peers. They find that individuals from language groups with high average welfare use are more likely to live on welfare when residing in larger networks. The authors instrument network size- the relative share of a language group in an area (Public Use Microdata Areas -PUMAs) - by the size of the same network at a higher level of aggregation (MSAs). ${ }^{5}$ While these last two papers propose more general methods, their application requires strong assumptions about present networks not being predetermined by historical ones in the first case and selection effects not being equally strong at higher levels of aggregation in the second.

We define network effects following Bertrand, Luttmer and Mullainathan [2000] but propose a different instrument for networks that relies on the exogenous variation in the accessibility of Spanish provinces by different means of transportation combined with information on how migrants from each country initially entered Spain. This instrument results particularly suitable for a country like Spain that can be reached by several means of transportation and whose migration experience is relatively recent. As time passes, migrants who tend to be more mobile than natives, are likely to move around the country weakening the power of this instrument.

Our paper is also related to the literature on individuals' remittance sending behavior which has mostly focused on testing migrants' motives for sending money home. Rapoport and Doquier [2006], in a comprehensive survey of the empirical and theoretical literature, distinguish between individual (altruism, exchange, strategy) and household motives (insurance, inheritance). ${ }^{6}$ Empirical results for the predominance of either motive are mixed, but literature has established some clear determinants for sending remittances. How much to remit seems to be positively related to migrants' income and ties with the country of origin and negatively with new bonds formed in and with the host country. Studies for Germany by Dustmann and Mestres [2010] and Sinning [2011] find that immigrants planning to stay longer in the host country send fewer remittances. Positive effects of higher income on remittances have been found for migrants from very different countries such as Botswana (Lucas and Stark [1985]), Nicaragua and El Salvador (Funkhouser [1995]) or Turkey, Greece, Yugoslavia, Italy, and Spain (Merkle and Zimmermann [1992]). A recent paper by Joseph, Nyarko and Wang [2015] considers remittance sending behavior over time of migrants in the United Arab Emirates. The authors find that individuals send more remittances as their earnings increase, but only if such earning increases are observable in

\footnotetext{
${ }^{5}$ Also for the US, Andersson, Burgess, and Lane [2014] apply the same method and find positive migrant network effects for employment.

${ }^{6}$ Rapoport and Doquier [2006] state the need for further research "on the social determinants of remittances, possibly in connection with the social networks literature" (pg. 1171).
} 
countries of origin. In line with most of these findings, in our estimations we also observe that income and return intentions are positively related to the amount of remittances sent.

To the best of our knowledge the current paper is the first to estimate the causal effect of networks on individuals' remittance sending behavior in the context of many different origin countries and to test for potential mechanisms, finding evidence for information sharing. In the spirit of findings in literature on the effect of migrant networks on trade flows (e.g. Herander and Saavedra [2005] or Peri and Requena-Silvente [2010]), we also find evidence for macroeconomic effects of networks. For a subset of countries that all receive large remittance flows from Spain (corridor countries), we find on average lower cost spreads between the most expensive and cheapest provider for countries characterized by high remittances and stronger networks, suggesting that network effects might be competition-enhancing. The remainder of the paper is organized as follows. Section 2 presents the methodology used. Section 3 describes our data. In Section 4 we present and discuss our results, and Section 5 concludes.

\section{Methodology}

As mentioned before, estimating network effects, or addressing the question if individuals replicate the behavior of those around them, is not a straight-forward task. To illustrate the difficulties that arise, let us first consider a rather "naive" approach that regresses individual behavior on average behavior of co-nationals living close by

$$
R_{i j k}=\overline{R_{j, k}} \alpha+X_{i} \beta+\gamma_{j}+\delta_{k}+\epsilon_{i j k}
$$

where $R_{i j k}$ denotes remittances of individual $i$ currently residing in municipality $j$ from country of origin $k$, and $\overline{R_{j, k}}$ is the mean quantity remitted by individuals from the same country of origin who live in the same municipality. $X_{i}$ denotes individual characteristics, $\gamma_{j}$ and $\delta_{k}$ are municipality and country dummies respectively, and $\epsilon_{i j k}$ are standard errors which we cluster at the country-municipality level. However, depending on the size of the immigrant group in the municipality, individual $i$ 's remittance behavior will affect $\bar{R}_{j, k}$ which hence cannot be used as an independent variable.

An improvement of the model above, as proposed by Borjas [1995], aggregates outcomes by country of origin at the national level, obtaining so-called "cultures." For countries with a significant representation in the host country, these "cultures" are unlikely to be affected by an individual's actions. The effect of "cultures" on individual's remittance 
sending behavior can be estimated as follows:

$$
R_{i j k}=\overline{R_{k}} \alpha+X_{i} \beta+\gamma_{j}+\epsilon_{i j k}
$$

where $\overline{R_{k}}$ is the mean quantity remitted by individuals from country $k$. However, given that $\overline{R_{k}}$ only varies at the country level fixed effects $\delta_{k}$ cannot be included in this regression. This implies that we are unable to control for other unobserved characteristics of countries that might influence individuals' remittance sending behavior (e.g. cultural aspects like generosity, strength of family ties, etc.). ${ }^{7}$

Alternatively, one could also aggregate the behavior of all migrants at the municipality level, independently of their country of origin, and estimate:

$$
R_{i j k}=\overline{R_{j}} \alpha+X_{i} \beta+\delta_{k}+\epsilon_{i j k},
$$

where $\overline{R_{j}}$ is the mean quantity remitted by migrants in municipality $j$. In this regression in turn we need to exclude $\gamma_{j}$ and are hence unable to control for other unobserved characteristics of municipalities that might influence individuals' remittance sending behavior (e.g. local labor market particularities, welfare policies implemented by the municipality, etc.).

To be able to control for unobserved factors at both the country and municipality level, we need average behavior to vary along both dimensions while at the same time we have to avoid running into the reverse causality problem present in Equation 2.1. Bertrand, Luttmer and Mullainathan [2000]'s definition of network effects is able to achieve this. The authors consider that network effects are present if individuals imitate the average group behavior when residing in locations with a strong presence of their peers. In line with this idea we define network effects as follows:

$$
\text { Network effects }{ }_{j k}=\overline{\overline{R_{k}}} \times \operatorname{Rep}_{j, k},
$$

where $\overline{\overline{R_{k}}}=\overline{R_{k}}-\bar{R}$ denotes the difference between average remittances of individuals from country $k$ and average remittances by any migrant in Spain $(\bar{R})$, and $\operatorname{Rep}_{j, k}$, denotes the relative representativeness of individuals from country $k$ in municipality $j$. In particular,

\footnotetext{
${ }^{7}$ As Bertrand, Luttmer and Mullainathan [2000] point out, this regression is affected by the socalled reflection problem as first defined by Manski [1993] which prevents us from interpreting a positive estimate of the coefficient $\alpha$ as evidence for network effects. The authors interpret this problem as essentially equivalent to the presence of two types of biases due to omitted variables regarding: (i) personal characteristics and (ii) neighborhood characteristics. Our baseline estimation addresses the latter by including municipality fixed effects and the former by instrumenting for networks.
} 
this last term is defined as the natural logarithm of the relative representativeness of individuals from country $k$ in municipality $j$ :

$$
\operatorname{Rep}_{j, k}=\ln \left(\frac{\operatorname{Pop}_{j, k} / \text { Pop }_{j}}{\operatorname{Pop}_{k} / \text { Pop }}\right) \text {. }
$$

Depending on a country's average remittance sending behavior or remittance "culture" and the representativeness of individuals from this country in a certain municipality, we can distinguish four different cases for network effects displayed below:

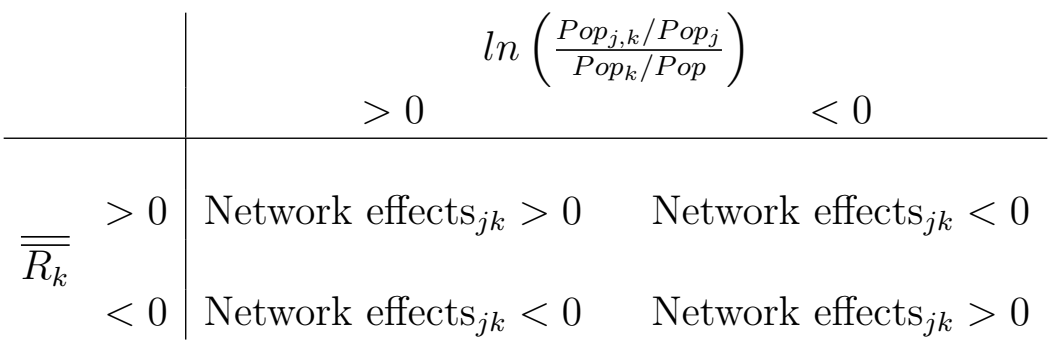

We hence estimate positive network effects if individuals from above-average (belowaverage) remitting countries who live in municipalities where their country group is overrepresented (underrepresented) remit relatively more than individuals from these same countries living in smaller (larger) networks; i.e. where they are underrepresented (overrepresented). When presenting our results we will analyze which of these subgroups drives the aggregate effect.

Note that the current specification of network effects has the advantage of allowing us to differentiate individuals along two dimensions: (i) the representativeness of their country in their municipality, as well as (ii) their country's average remittance sending behavior. To highlight why this is important consider an alternative specification that interacts representativeness with the average remittance sending behavior of the country ("culture") instead of its difference with the national average. Under such a specification individuals from countries that remit little and who live in very large networks could be assigned the exact same value for network effects as individuals from countries that remit much but who live in somewhat smaller (though still overrepresented) networks. We would thus only be able to distinguish individuals by the representativeness of their country of origin in their municipality. However, for network effects to operate imitation plays a crucial role, and it depends on the average behavior of co-nationals. Hence, we also want to differentiate individuals by "culture." 
On the other hand, without the logarithmic transformation of our variable for representativeness, individuals from countries that remit much who live in small networks could be assigned the exact same value for network effects as individuals from somewhat lower (though still above average) remitting countries living in larger networks. Only specifications such as the one proposed by Bertrand, Luttmer and Mullainathan [2000] allow us to clearly distinguish between how individual's remittance sending behavior is affected by (i) the representativeness of an individual's country of origin in his or her municipality and (ii) "culture", i.e. average remittances sent by co-nationals. Put otherwise, it allows us to account for "who" is being imitated and "what" is being imitated. While subtracting the national average from the average remittance sending behavior of a country is a monotone transformation, the same cannot be said about the logarithmic transformation of our variable for representativeness. Hence, we make sure that our main results are robust to an alternative specification that considers representativeness without the logarithmic transformation.

To estimate the effect of networks on individual's remittance sending behavior, we thus rewrite our model in the following way:

$$
R_{i j k}=\left(\overline{\overline{R_{k}}} \times \operatorname{Rep}_{j, k}\right) \alpha+X_{i} \beta+\gamma_{j}+\delta_{k}+\operatorname{Rep}_{j, k} \theta+\epsilon_{i j k} .
$$

We do not include the non-interacted term, $\overline{\overline{R_{k}}}$, by itself because it is captured by country fixed effects.

However, if we were to estimate Equation 2.4 by ordinary least squares the problem of self-selection and in particular differential self-selection by migrants' "cultures" would still persist. Specifically, such an OLS estimation of network effects would be subject to a positive bias if among individuals from countries where average remittances are high, those who remit more decided to reside in municipalities with many co-nationals. On the other hand, a negative bias would be present in an OLS estimation of Equation 2.4 if among individuals from countries where average remittances are low, those who remit more decided to reside in municipalities with many co-nationals. To clearly isolate network effects on remittance sending behavior from effects arising from residential self-selection, we estimate Equation 2.4 using instrumental variables.

\subsection{Instrumenting for network effects}

We follow Gonzalez and Ortega [2012], and we predict the number of migrants from each country that settle in each location by considering how accessible the location is by different modes of transportation, and how migrants from different countries initially arrived 
in Spain. For Spain data on the accessibility of municipalities is not available, and hence our instrument is constructed at a higher level of aggregation, provinces.

We distinguish between four modes of physical accessibility: by air and land, and for sea access we further differentiate between regular boats and makeshift rafts. ${ }^{8}$ To define accessibility $a_{p, m}$ for each province $p$ and mode $m$, we use information on the share of international arrivals in province $p$ by plane and boat. For accessibility by land (car, bus, or train) $a_{p, l a n d}$, we consider the relative distance from province $p$ 's capital city to the French border along major highways. To assess a province's accessibility by makeshift rafts we consider if it has a coast line that can be reached by such rafts (i.e. Spain's Mediterranean coast and the Canary islands). For the other three modes of transportation measures are normalized such that their sum up to one (across all provinces), $\sum_{p} a_{p, m}=1 \forall m=$ air, land, boat; i.e. each province is assigned its share of boat and air travel passengers and its relative distance to the French border. In a second step, we calculate the share of all individuals born in country $k$ who used each mode of transportation, $e_{k, m}$ when initially entering Spain for the first time. By construction, for any country $k$ these terms also add up to one across all four modes of transportation, i.e. $\sum_{m} e_{k, m}=1 \forall k$.

Finally, for all modes but makeshift rafts, we multiply the two terms, $a_{p, m}$ and $e_{k, m}$, and we obtain an indicator for the accessibility by each mode of transportation for each province from the point of view of each country of origin. We then sum these three terms, and we add a product composed of an indicator for accessible coast line and arrivals by makeshift rafts. This way we obtain a measure for the overall degree of accessibility of each province from the point of view of each country of origin:

$$
\lambda_{p, k}=a_{p, l a n d} e_{\text {land }, k}+a_{p, a i r} e_{a i r, k}+a_{p, b o a t} e_{b o a t, k}+D_{p, c o a s t} e_{r a f t, k} .
$$

To predict the number of migrants from each country in each province, we multiply the degree of accessibility $\left(\lambda_{p, k}\right)$ by the number of foreign-born individuals from country $k$ residing in Spain $\left(F B_{k}\right)$ :

$$
\widehat{P_{o p}, k}=\lambda_{p, k} F B_{k} .
$$

This predictor assigns more migrants from Europe who tend to initially enter Spain by bus or car to landlocked provinces, while Southern provinces with coastlines are assigned more immigrants from Africa. Finally, we assign more migrants from Latin America to

\footnotetext{
${ }^{8}$ Spain's Mediterranean coastline together with the coasts of the Canary Islands sum 3,561 km, and according to the Spanish Ministry of Internal Affairs [2007] in 2006 and 2007 39,180 and 18,057 illegal immigrants respectively arrived on makeshift rafts. While according to the same source the vast majority was repatriated, controlling for this route of access is potentially important.
} 
regions with important international airports.

\subsubsection{Adjustment: Tourism}

Spain is one of the most important tourist destinations in the world. In 2007, almost 60 million tourists visited the country. These movements of individuals potentially bias our accessibility measure. Hence, in order to obtain a better predictor for the representativeness of migrants in each municipality we adjust our instrument for individuals who could actually be tourists. Under the assumption that preferred transportation modes for individuals from different countries are similar for tourists and immigrants, - with the clear exception of makeshift rafts - our adjustment also uses $e_{k, m}$, the share of individuals born in country $k$ who initially entered Spain using each mode of transportation $m .{ }^{9}$ Data on the number of tourists are only available for each autonomous region which represent a higher level of aggregation than provinces, and we hence combine the measure $e_{k, m}$ with the share of tourists arriving by each mode of transportation in each autonomous region $t_{r, m} \cdot{ }^{10} \mathrm{We}$ then estimate the share of tourists from each country of origin that would arrive in each region by different means of transportation: $\rho_{r, k}=t_{r, \text { land }} e_{l a n d, k}+t_{r, a i r} e_{a i r, k}+t_{r, b o a t} e_{b o a t, k}$.

In a second step, we predict where immigrants would reside if all of them were tourists, by multiplying the term $\rho_{r, k}$ with $F B_{k}$, the foreign-born population from country $k$ :

$$
\widehat{T R_{r, k}}=\rho_{r, k} F B_{k}
$$

and we use this term to adjust our initial instrument.

We then estimate our main model by a two-step IV procedure that circumvents the problem of self-selection present in Equation 2.4 and that includes the correction of our initial instrument for tourism. The first step estimates:

$$
\begin{aligned}
& \overline{\overline{R_{k}}} \times R e p_{j, k}=\left(\overline{\overline{R_{k}}} \times \widehat{R e p_{p, k}}\right) \alpha+\left(\overline{\overline{R_{k}}} \times \widehat{T R_{r, k}}\right) \kappa+X_{i} \beta+\gamma_{j}+\delta_{k}+\widehat{R e p_{p, k}} \theta+\widehat{T R_{r, k}} \omega+\epsilon_{i j k} \\
& \operatorname{Rep}_{j, k}=\left(\overline{\overline{R_{k}}} \times \widehat{R e p_{p, k}}\right) \alpha+\left(\overline{\overline{R_{k}}} \times \widehat{T R_{r, k}}\right) \kappa+\widehat{R e p_{p, k}} \theta+\widehat{T R_{r, k}} \omega+X_{i} \beta+\gamma_{j}+\delta_{k}+\epsilon_{i j k}
\end{aligned}
$$

where

$$
\widehat{\operatorname{Rep}_{p, k}}=\ln \left(\frac{\widehat{\operatorname{Pop}_{p, k}} / P_{o p_{p}}}{\operatorname{Pop}_{k} / P o p}\right)
$$

\footnotetext{
${ }^{9}$ We sum the share of migrants entering by makeshift rafts to the share of those entering by boat.

${ }^{10}$ We predict this share $\left(t_{r, m}\right)$ by multiplying $T_{r}$, the number of tourists in each region by $s_{m}$, the share of tourist arrivals in Spain by each mode of transportation $m$, where $m=$ air, land, sea and $t_{r, m}=T_{r} s_{m}$.
} 
uses the predicted number of individuals from each country of origin in each province as specified in Equation 2.5. We expect the predicted representativeness of migrants in each province to be positively correlated with the representativeness of migrants in each municipality, and we expect a negative correlation with the predicted number of tourists.

The second step of the estimation uses the predicted representativeness at the municipality level and the predicted interaction term in our main regression:

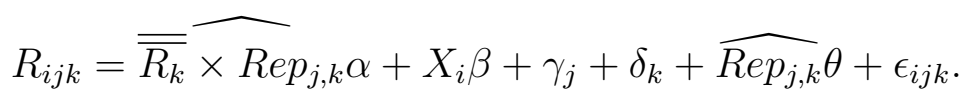

Equation 2.7 represents our baseline specification.

The validity of our instrument relies on the fact that migrants' initial arrival mode in Spain is determined by geographical factors which are independent of remittance sending behavior. ${ }^{11}$ In particular, our instrument combines migrants' arrival mode with the accessibility of each province by different modes of transportation. Given that the latter is approximated by the relative distance to France but also by share of arrivals by plane and boat in each province, there could exist some concern that our measure of accessibility reflects economic opportunities which also determine remittance sending behavior. However, we cannot think of any reason that over the course of many years such opportunities would be systematically related to how immigrants from a certain country initially arrive in Spain. Note that province fixed effects in our first step estimation capture any difference in economic opportunities across provinces. One might still be concerned that even arrival modes could be endogenous. For instance if family members of migrants who send more remittances can subsequently afford to arrive in Spain via more expensive means of transportation (plane vs car). However, country of origin fixed effects in our first stage estimation control for this.

\footnotetext{
${ }^{11}$ For countries in Latin America the only valid arrival mode is by plane, while for countries in Europe or Africa the choice between car or plane or boat or plane is most likely determined by closeness of airports in countries or origin or routes covered by airlines at a certain point in time (when migrants first arrived in Spain), aspects that are both independent of individual remittance sending behavior.
} 


\section{Data}

\subsection{Data bases}

For our analysis we use data from the Spanish National Immigrant Survey ("Encuesta Nacional de Inmigrantes"), a unique survey carried out in 2007. The survey interviewed 15,465 foreign-born citizens who were living in Spain at the time of the interview, and who had been (or intended to stay) in Spain for at least one year. The survey asked questions about a wide variety of aspects, among others: socio-demographic characteristics, labor market activity, contacts with Spanish civil society and contacts with the society of origin. ${ }^{12}$ We have information on migrants' municipality of residence and the mode of transportation they used when they first arrived in Spain. Of particular interest for our analysis, the survey also asked about the amount of remittances and how remittances were sent.

We rely on the Spanish Town Hall Census for data on the number of individuals from each country of origin in each municipality. The Census is an administrative register that contains information on all individuals residing in a municipality. Its main advantage is its accuracy regarding the number of immigrants from each country that live in a municipality. Most immigrants in Spain are registered with their municipality regardless of whether they are otherwise documented or not, because there are strong incentives to do so. Registration with the municipality provides access to basic medical care, education for children, and many other social services. ${ }^{13}$ Furthermore, even undocumented migrants can be certain that registering will not entail any negative legal consequences. ${ }^{14}$ From the Town Hall Census we also obtain data on total population in each municipality, province, and autonomous region, as well as information about the overall presence of individuals from each country in Spain.

We use data from additional sources to construct our instrumental variables. Regarding the accessibility of each province by plane we consider data from the operator of Spanish airports (AENA) on the annual number of passengers arriving at each airport. We use

\footnotetext{
${ }^{12}$ For further information on the survey design and methodology see Reher and Requena [2009] or the methodological description provided by the Spanish National Statistics Institute (INE): http://www . ine.es/en/daco/daco42/inmigrantes/inmigra_meto_en.pdf

${ }^{13}$ This is no longer the case. In 2012 a law was passed ("Real Decreto 1192/2012") that excludes undocumented migrants from access to medical care.

${ }^{14}$ Town Hall Censuses are regularly updated. It is compulsory for non-EU immigrants to re-register in the Town Hall Census every two years and records of EU immigrants who do not re-register every two or five years will be automatically deleted from the Census.
} 
data from the Ministry of Infrastructure for the number of passengers arriving by boat at each port. We used Google Maps to measure the distance between each province's capital city and the French border along major highways. For adjusting our instruments for tourism, we rely on survey data for 2007 published by the Ministry of Industry, Energy and Tourism regarding the number of tourist entries by means of transportation as well as the number of foreign travelers who stay overnight in each one of the Spanish autonomous regions ("Encuesta de Ocupacion Hotelera").

Finally for a subset of ten countries that receive large amounts of remittances from Spain (so called corridor countries), we have data for 2008 from the World Bank on providers and prices charged for sending remittances. This data allows us to explore the relationship between network effects and costs of sending remittances.

\subsection{Sample selection}

We restrict our sample to individuals from countries of origin with at least 5,000 individuals living in Spain. ${ }^{15}$ We also exclude from our analysis two mid-size Spanish cities, Ceuta and Melilla, which are located on the African continent. We do so for two reasons: (i) Given that these cities have an independent administrative status ("autonomous cities") including them leads to artificially more heterogeneity in all our province-based measures and (ii) the vast majority of migrants in these cities arrives from Africa by land which makes it impossible for our instrument to predict migration to these cities. These restrictions leave us with data for 12,656 individuals from 59 different countries of origin distributed among all 50 provinces and 17 autonomous regions. ${ }^{16}$

\subsection{Descriptive statistics}

Table 3.1 displays summary statistics (mean, standard deviation, minimum, and maximum values) for our main sample. In order to maximize the number of individuals in our sample despite some missing variables, we construct indicators for missing information regarding education, income, and family living abroad (see Table A2 of the Appendix for details). Individuals in our sample remitted on average around $670 €$ during the course of a year, ranging from no remittances at all to $60,000 €$. Regarding individual characteris-

\footnotetext{
${ }^{15}$ Our main results are robust to using larger samples that include countries of origin with at least 2,000 individuals living in Spain.

${ }^{16}$ See Figure A-2 in the Appendix for two maps displaying Spain's 50 provinces on the European continent and its 17 autonomous regions.
} 
tics, half of all migrants in our sample are men, and they are on average around 40 years old. Slightly more than half are married, and they live in households with between two and three additional members. Most have secondary education (53\%) followed by tertiary $(21 \%)$ and primary education. Around $12 \%$ has not completed primary education. Approximately $18 \%$ of migrants in our sample completed their education in Spain. The majority is employed (65\%), and average monthly income is around $700 €$. Around $24 \%$ of migrants indicate intentions to bring family members to Spain, while only $7 \%$ say that they intent to return to their country of origin within the next five years. ${ }^{17}$ In the case of $5 \%$ and $13 \%$ of migrants, children and spouses respectively reside in the country of origin. Numbers are much higher for other family members: $35 \%, 29 \%$, and $47 \%$ have mother, father, and siblings respectively living in their country of origin. Regarding network variables, the average representativeness of a country in a municipality is 5 times larger than the national average. Ranging from a close to zero representation to more than 300 times more Norwegians in Alfàs del Pi (Alicante) compared to their national average.

The logarithmic transformation mitigates this difference in variability somewhat. Average population size by province is 2.7 million, ranging from 93,000 in the province of Soria to more than 6 million in Madrid. Individuals from most countries of origin typically entered Spain initially by plane, followed by arrivals via roads (or railroads).

In Table A1 of the Appendix we report for each of the 59 countries of origin in our sample averages for the following key variables: presence in Spain and in our sample, remittances sent, close family (spouse or children) living abroad, age, and monthly labor income. There is large variation in average remittances sent, ranging from no remittances at all sent by migrants from Switzerland or Australia to $2,117 €$ sent by individuals from Mauritania. For country averages we observe no clear relationship between remittances sent and monthly labor income. However, for countries of origin with a large fraction of individuals reporting that their close family lives abroad, average remittances are higher. ${ }^{18}$ Summary statistics for additional variables used in our estimations for heterogeneity and mechanisms of network effects (years in Spain, continent of origin, remittance channels, etc.) as well as information on missing variables are displayed in Table A2 of the Appendix. Note that on average, migrants in our sample have been living in Spain for 11

\footnotetext{
${ }^{17}$ The legislation in force during 2006/2007 regarding family reunification with spouse, children, and elderly parents required that non-EU migrants had renewed their residence permit at least once, and that they had adequate housing and sufficient economic means to maintain their family.

${ }^{18}$ Retiree migration mainly from Nordic countries to the South of Spain explains the higher average age observed for migrants from these countries. The same phenomenon explains the relatively high share of close family living abroad (their adult children) as well as the fact that average labor income is low, as pension receipts are not included in this measure.
} 
Table 3.1: Summary statistics (population-weighted): Main Sample

\begin{tabular}{|c|c|c|c|c|}
\hline Variable & Mean & Std. Dev. & Min. & Max. \\
\hline \multicolumn{5}{|l|}{ Remittances: } \\
\hline Remittance sent in $2006, €$ & 670.286 & $1,758.526$ & 0 & 60,000 \\
\hline \multicolumn{5}{|l|}{ Individual Characteristics: } \\
\hline Male & 0.511 & 0.5 & 0 & 1 \\
\hline Age & 39.371 & 14.511 & 18 & 98 \\
\hline Married & 0.536 & 0.499 & 0 & 1 \\
\hline Household members & 3.634 & 1.738 & 1 & 18 \\
\hline \multicolumn{5}{|l|}{ Education: } \\
\hline Primary & 0.144 & 0.351 & 0 & 1 \\
\hline Secondary & 0.531 & 0.499 & 0 & 1 \\
\hline Tertiary & 0.212 & 0.409 & 0 & 1 \\
\hline \multicolumn{5}{|l|}{ Host country ties: } \\
\hline$\overline{\text { Educated in Spain }}$ & 0.176 & 0.381 & 0 & 1 \\
\hline Employed & 0.648 & 0.478 & 0 & 1 \\
\hline Monthly income, $€$ & 698.374 & 843.353 & 0 & 15,000 \\
\hline Participation in elections & 0.207 & 0.405 & 0 & 1 \\
\hline Intentions to bring family & 0.241 & 0.428 & 0 & 1 \\
\hline \multicolumn{5}{|l|}{ Home country links: } \\
\hline Return intentions next 5 years & 0.068 & 0.251 & 0 & 1 \\
\hline Spouse abroad & 0.048 & 0.214 & 0 & 1 \\
\hline Children abroad & 0.129 & 0.335 & 0 & 1 \\
\hline Mother abroad & 0.349 & 0.477 & 0 & 1 \\
\hline Father abroad & 0.285 & 0.451 & 0 & 1 \\
\hline Sibling abroad & 0.467 & 0.499 & 0 & 1 \\
\hline \multicolumn{5}{|l|}{ Network variables: } \\
\hline Representativeness, municipality & 4.923 & 11.373 & 0.01 & 338.013 \\
\hline Log Representativeness, municipality $\left(\operatorname{Rep}_{j, k}\right)$ & 0.766 & 1.232 & -4.619 & 5.823 \\
\hline Individuals from each country of origin in municipality & 6,072 & 16,948 & 2 & 111,308 \\
\hline Individuals from each country of origin in province & 27,180 & 35,722 & 4 & 150,263 \\
\hline Population in province & $2,693,712$ & $2,226,465$ & 93,503 & $6,008,183$ \\
\hline \multicolumn{5}{|l|}{ Country means for arrival mode: } \\
\hline Land (Bus,car, train) & 0.290 & 0.320 & 0 & 0.911 \\
\hline Plane & 0.610 & 0.371 & 0.088 & 1 \\
\hline Boat & 0.093 & 0.204 & 0 & 0.634 \\
\hline Makeshift raft & 0.007 & 0.023 & 0 & 0.333 \\
\hline
\end{tabular}

years, and hence on average they initially arrived in Spain in the late 1990's. In Table A3 of the Appendix we report World Bank data on the prices for sending remittances charged by the least and most expensive providers in Spain. 


\section{Results}

\subsection{Presence of network effects}

We explore whether migrants' remittance choices are influenced by network effects. Table 4.1 displays coefficients for the different measures of network effects discussed before (for the full set of coefficients see Table A4 in the Appendix). The first column reports the results from estimating Equation 2.1 that considers the most "naive" way of measuring networks, using the average amount remitted by co-nationals who live in the same municipality. The coefficient is positive and highly significant, indicating that individuals who live in municipalities where their co-nationals remit much, remit relatively more.

Table 4.1: Main estimation: Network effects

\begin{tabular}{|c|c|c|c|c|c|}
\hline & (1) & $(2)$ & $(3)$ & $(4)$ & $(5)$ \\
\hline Mean remit, mun. and country & $\begin{array}{c}0.972 \\
(0.017)^{* * *}\end{array}$ & & & & \\
\hline Mean remit, country & & $\begin{array}{c}0.709 \\
(0.322)^{* *}\end{array}$ & & & \\
\hline Mean remit, municipality & & & $\begin{array}{c}0.493 \\
(0.203)^{* *}\end{array}$ & & \\
\hline Network effects & & & & $\begin{array}{l}0.051 \\
(0.035)\end{array}$ & $\begin{array}{c}0.609 \\
(0.242)^{* *}\end{array}$ \\
\hline Representativeness & & & & $\begin{array}{c}4.990 \\
(21.755)\end{array}$ & $\begin{array}{r}-56.967 \\
(95.136)\end{array}$ \\
\hline Municipality fixed effects & $\mathrm{x}$ & $\mathrm{x}$ & & $\mathrm{x}$ & $\mathrm{x}$ \\
\hline Country fixed effects & $\mathrm{x}$ & & $\mathrm{x}$ & $\mathrm{x}$ & $\mathrm{x}$ \\
\hline Obs. & 12,656 & 12,656 & 12,656 & 12,656 & 12,656 \\
\hline$R^{2}$ & 0.544 & 0.251 & 0.251 & 0.251 & 0.228 \\
\hline
\end{tabular}

The dependent variable is the amount of euros that individuals report to have remitted over the course of the previous year. The coefficients are marked with * if the level of significance is between $5 \%$ and $10 \%, * *$ if the level of significance is between $1 \%$ and $5 \%$ and $* * *$ if the level of significance is less than $1 \%$. Columns 1 to 4 are estimated by population-weighted OLS, column 5 is estimated by population-weighted 2SLS. All regressions contain the following individual characteristics: gender, age, marital status, household members, education, education received in Spain, family living abroad, income, employment, return intentions, participation in elections, intentions to bring family (see Table A4 in the Appendix for the full set of results). Standard errors are clustered at the municipality-country level.

However, this result could be driven by the effect that individual remittances have on the country average in the municipality. Column 2 reports the coefficient for the improved model (see Equation 2.2) that uses national averages by country of origin instead. This coefficient is somewhat smaller but still positive and significant at the $5 \%$ level. Individuals from countries that remit a lot also tend to remit more. In column 3 the coefficient 
on average remittances at the municipality level is only half the size of the coefficient in column 1, which shows that the correlation between individuals' remittances and group averages is lower when considering all migrants within a municipality independently of their country of origin. Column 4 reports OLS estimates for Equation 2.4 using Bertrand, Luttmer and Mullainathan [2000]'s definition of network effects which allows us to control for unobserved municipality and country specific factors. Coefficients for network effects and representativeness in this estimation are positive but not significant. When comparing the coefficient on network effects to the one from the IV estimation displayed in the last column, we observe that the OLS estimation suffers from a negative bias. As discussed before, this is driven by differential self-selection of individuals into their place of residence. In particular, individuals with a relatively high (low) propensity to remit and who belong to below-average (above-average) remitting countries tend to move to municipalities where their co-nationals concentrate. Alternatively, individuals with a relatively high (low) propensity to remit and who belong to above-average (below-average) remitting countries tend to move to municipalities with few co-nationals.

Results from our IV estimation that is able to set aside differential self-selection indicate a positive and very significant coefficient for network effects. This shows that individuals from above-average remitting countries increase the amount of remittances they send as a consequence of living surrounded by relatively many co-nationals and/or that those from below-average remitting countries decrease the amount of remittances they send as a result of living in larger networks. We test which group is driving the aggregate result by including interaction terms of network effects with indicator variables for individuals who are from above-average remitting countries and for those who live in municipalities where their country is overrepresented. Results from these two regressions show that network effects are exclusively driven by individuals from above-average remitting countries (see Table A5 in the Appendix).

While we find positive and significant network effects, these are not easily quantifiable. Following one possible approach suggested in Bertrand, Luttmer and Mullainathan [2000], we estimate that networks amplify individuals' remittance choices by $56.3 \%$. This implies that if in the absence of networks a sudden shock leads to a 1 percentage point increase in individual remittances - for instance due to a natural disaster in the home country then networks give rise to an increase of 1.6 percentage points. ${ }^{19}$ However, as Bertrand, Luttmer and Mullainathan [2000] point out, this number has to be taken with a grain of

\footnotetext{
${ }^{19}$ On pages 1039-1040 Bertrand, Luttmer and Mullainathan [2000] show how this amplification effects of networks can be calculated. First for each country $x_{k}=1 /\left(1-\alpha \overline{R e p_{k}}\right)-1$ is calculated where $\alpha$ is the coefficient on network effects from our IV estimation, and $\overline{R e p_{k}}$ is the average representativeness of country $k$. Then the weighted average over all countries' $x_{k} s$ provides the estimate of $56.3 \%$.
} 
salt because its calculation assumes that any change in a country's average remittances implies a one-to-one change in its remittance "culture." A somewhat looser interpretation suggests that the amount of remittances is only indicative for how co-nationals can affect individuals' remittance behavior. In this case, a shock that increases a country's average remittances may not change network effects as much as suggested by our simple calculation, and hence the amplification would be smaller. First stage estimations for our instrument of network effects and representativeness are displayed in Table 4.2. Our instruments are highly significant, and the adjustment for tourism shows the expected sign.

Table 4.2: First stage

\begin{tabular}{|c|c|c|}
\hline & $\frac{\text { Network effects }}{(1)}$ & $\frac{\text { Representativeness }}{(2)}$ \\
\hline$\overline{\text { Instrument network effects }}$ & 0.113 & -.00007 \\
\hline$\left(\overline{\overline{R_{k}}} \times \widehat{R e p_{p, k}}\right)$ & $(0.014)^{* * *}$ & $(0.00002)^{* * *}$ \\
\hline Instrument representativeness & 8.421 & 0.24 \\
\hline$\left(\widehat{R e p_{p, k}}\right)$ & $(6.116)$ & $(0.014)^{* * *}$ \\
\hline Adjustment tourism & $\begin{array}{c}-.009 \\
(0.001)^{* * *}\end{array}$ & $\begin{array}{l}4.90 \mathrm{e}-06 \\
(2.35 \mathrm{e}-06)^{* *}\end{array}$ \\
\hline Interaction adjust. tourism & $\begin{array}{c}6.66 \mathrm{e}-09 \\
(1.04 \mathrm{e}-08)\end{array}$ & $\begin{array}{l}-1.29 \mathrm{e}-10 \\
(1.81 \mathrm{e}-11)^{* * *}\end{array}$ \\
\hline Obs. & 12,656 & 12,656 \\
\hline$R^{2}$ & 0.629 & 0.537 \\
\hline
\end{tabular}

The dependent variables are "network effects" $\left(\overline{\overline{R_{k}}} \times \operatorname{Rep}_{j, k}\right)$ in column $(1)$ and "Representativeness" $\left(\operatorname{Rep}_{j, k}\right)$ in column (2). The coefficients are marked with * if the level of significance is between $5 \%$ and $10 \%$, ** if the level of significance is between $1 \%$ and $5 \%$ and $* * *$ if the level of significance is less than $1 \%$. The regressions are estimated by population-weighted OLS and contain all individual characteristics included in our main estimation (see Table A4) as well as municipality and country dummies. Standard errors are clustered at the municipality-country level.

Regarding other determinants of individuals' remittance sending behavior and similar to findings in literature, we also estimate a positive correlation of income and employment and bonds with the home country and a negative correlation of ties with the host country. With respect to the latter for all but the first specification, we find that in particular being educated in Spain is related to significantly lower remittances. On the other hand, 
having children, spouse, mother, or father living abroad as well as return intentions - all indicators of bonds with one's country of origin - are related to more remittances. We also find that individuals who intend to bring their family to Spain - something that may indicate both, ties with the home and links to the host country - send more remittances, see Table A4 in the Appendix.

However, some of these additional aspects of remittance sending behavior like employment and income have been shown to be affected by networks themselves. This could potentially bias our estimates. Following Bertrand, Luttmer and Mullainathan [2000] we thus check whether removing controls from our regression affects results. In addition, if individual unobserved factors were mainly driving our results, one would expect that increasing the number of unobservables by removing observables would alter our coefficients. In the first column of Table 4.3 we report our IV coefficients for the most sparse regression that only includes country dummies. We then add municipality fixed effects in column two and additional groups of control variables one by one until arriving at our main specification in the last column. The coefficient on network effects is very stable across all specifications, and once municipality fixed effects are accounted for, the same is true for the coefficient on representativeness. This indicates that these controls are not affected much by network effects, and that individuals' unobservable characteristics are not driving our results. In Tables A6 and A7 of the Appendix we show that also our first stage estimations are robust to removing and adding controls.

Table 4.3: Main IV estimation: Network effects - removing controls

\begin{tabular}{lcccccc} 
& $(1)$ & $(2)$ & $(3)$ & $(4)$ & $(5)$ & $(6)$ \\
\hline Network effects & 0.693 & 0.651 & 0.656 & 0.637 & 0.588 & 0.609 \\
& $(0.223)^{* * *}$ & $(0.259)^{* *}$ & $(0.26)^{* *}$ & $(0.259)^{* *}$ & $(0.242)^{* *}$ & $(0.242)^{* *}$ \\
Representativeness & 125.674 & -34.254 & -37.564 & -43.346 & -40.073 & -56.967 \\
& $(80.652)$ & $(100.101)$ & $(99.226)$ & $(100.658)$ & $(96.858)$ & $(95.136)$ \\
Country fixed effects & $\mathrm{x}$ & $\mathrm{x}$ & $\mathrm{x}$ & $\mathrm{x}$ & $\mathrm{x}$ & $\mathrm{x}$ \\
Municipality fixed effects & & $\mathrm{x}$ & $\mathrm{x}$ & $\mathrm{x}$ & $\mathrm{x}$ & $\mathrm{x}$ \\
Gender, age, marital status & & & $\mathrm{x}$ & $\mathrm{x}$ & $\mathrm{x}$ & $\mathrm{x}$ \\
Education & & & $\mathrm{x}$ & $\mathrm{x}$ & $\mathrm{x}$ & $\mathrm{x}$ \\
Family abroad & & & & & $\mathrm{x}$ & $\mathrm{x}$ \\
Remaining controls & 12,656 & 12,656 & 12,656 & 12,656 & 12,656 & $\mathrm{x}$ \\
Obs. & 0.05 & 0.143 & 0.15 & 0.156 & 0.214 & 0.228 \\
$R^{2}$ & & & & & & \\
\hline \hline
\end{tabular}

The dependent variable is the amount of euros that individuals report to have remitted over the course of the previous year. The coefficients are marked with * if the level of significance is between $5 \%$ and $10 \%, * *$ if the level of significance is between $1 \%$ and $5 \%$ and $* * *$ if the level of significance is less than 1\%. All regressions are estimated by population-weighted 2SLS. Standard errors are clustered at the municipality-country level. Remaining controls refer to number of household members, income, employment, return intentions, participation in elections, and intentions to bring family. 


\subsubsection{Robustness: Sample}

In addition to removing controls we also check the robustness of our results along other dimensions. We first make sure that our results are driven by economic migrants, i.e. migrants from poorer countries. While there are also immigrants from France, Italy or the US who report to send money to their countries of origin these are likely to be idiosyncratic transfers, and they may be different from remittances. We hence re-run our main regression excluding from our sample individuals from countries whose GDP per capita in 2007 was higher than Spain's. While this reduces our sample by around one fourth, results in Table A10 are almost indistinguishable from those in our main estimation, confirming that our results are not driven by other types of money transfers.

We then check that results are not exclusively driven by individuals from certain countries of origin, in particular by those from the two largest groups in our sample, Moroccans and Romanians. The first two columns of Table A 8 display results for these different samples. Without Moroccans, network effects are smaller, while they are somewhat larger and more significant when excluding Romanians. On the other hand, individuals from the majority of African countries in our sample report to send rather large amounts of remittances. In the third column we show results for a sample that excludes individuals from Africa. Compared to our main estimation, network effects are only slightly smaller and remain significant at the 5\% level. Finally, the Spanish Balearic and Canary islands are the only provinces for which accessibility by land is undefined. This could potentially affect our results. Coefficients for a sample that excludes these provinces are displayed in column 4. Without considering migrants living on islands, network effects are somewhat larger.

Our main sample is limited to individuals from countries of origin with a representation of at least 5,000 individuals in Spain. However, coefficients in Table A9 in the Appendix show that our results are robust to using a sample that includes individuals from countries of origin with a representation of at least 2,000 individuals. As mentioned before, our results are also robust to an alternative definition of network effects that uses the simple ratio for relative representativeness without the logarithmic transformation. The coefficient on network effects in our IV estimation remains positive and significant at the $5 \%$ level (see Table A11 of the Appendix). 


\subsection{Heterogeneity of network effects}

Our results show that immigrants from above-average remitting countries remit more if they live in larger networks. However, network effects are likely to operate differently depending on a variety of individual characteristics such as cultural background, family situation, length of stay, or legal situation in Spain. To investigate this matter, we repeat our IV estimation interacting network effects with indicators for the following variables: "having Spanish nationality", "years lived in Spain", "children or spouse lives abroad" and five indicators for continent of origin. Table 4.4 displays the results. Network effects are negative for immigrants with Spanish nationality, and they decrease with years lived in Spain; see columns (1) and (2). Results in column (3) show that network effects for remittances are particularly strong for individuals whose spouse or children live abroad. When considering continents of origin, we only find significant effects for individuals from America. However, effects are also large - although probably due to reduced samples not

significant - for individuals from Africa, Asia, and Oceania. For Europeans the estimated coefficient is much smaller.

\subsection{Mechanisms of network effects}

How do network effects operate? In the introduction we suggested three direct mechanisms that could lead to individuals living surrounded by others from the same country of origin making similar remittance choices: (i) Migrant communities can help to maintain ties with the home country thus increasing the desire to remit, (ii) migrant communities can help to establish ties with the host country thus decreasing the desire to remit, and (iii) living surrounded by co-nationals, in particular if they remit much, might provide for better information about cost effective ways of sending money home. Given that we estimate positive network effects that are driven by individuals from above-average remitting countries who live in larger networks only mechanisms (i) and (iii) could be at work. We thus test for the presence of these mechanisms. Outcomes that could suggest that mechanism (i) operates are: return intentions or the desire for family reunification. Furthermore, owning a house in the country of origin could also be seen as an indicator for return intentions as could not participating in Spanish elections. We test for the relationship between network effects and all these outcomes but do not find any significant relationships. We also test if network effects on remittances operate indirectly through better employment opportunities or higher income related to living surrounded by many co-nationals from above-average remitting countries but find no support for this, see Table A12. However, note that our results do not exclude the possibility that migrant networks defined differently: i.e. not in terms of remittance sending behavior, could affect such 
Table 4.4: Heterogeneity of network effects

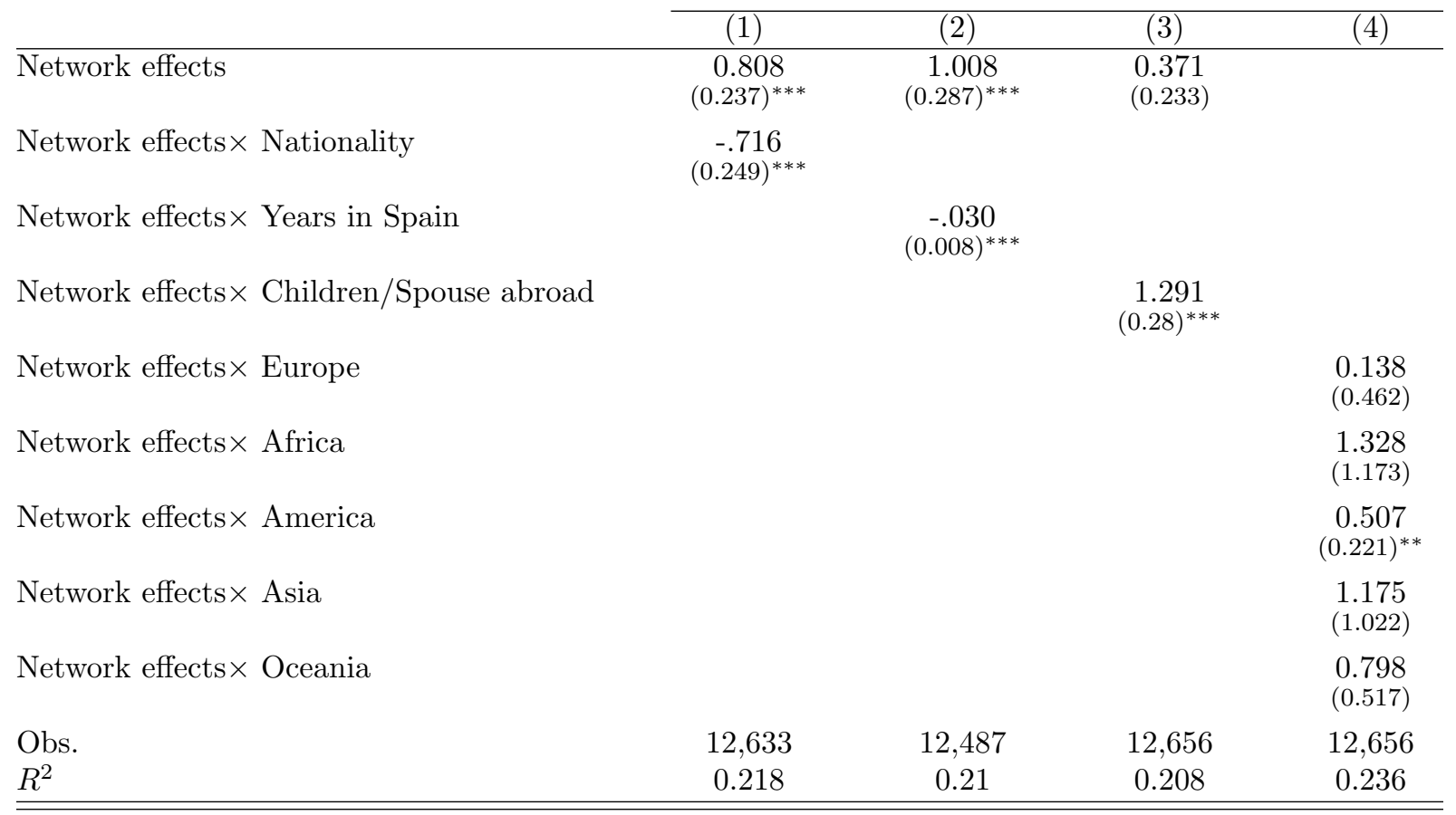

The dependent variable is the amount of euros that individuals report to have remitted over the course of the previous year. The coefficients are marked with * if the level of significance is between $5 \%$ and $10 \%,{ }^{*}$ if the level of significance is between $1 \%$ and $5 \%$ and $* * *$ if the level of significance is less than $1 \%$. All regressions are estimated by population-weighted 2SLS and contain all individual characteristics included in our main estimation (see Table A4) as well as municipality and country dummies. Additionally in columns (1) and (3) indicators for having Spanish nationality and children or spouse living abroad are included. Column(2) includes a variable indicating years lived in Spain and column (4) indicators for continent of origin. Standard errors are clustered at the municipality-country level.

outcomes for immigrants in Spain. Put otherwise we do not dismiss the possibility that social pressure, in the spirit of Chort, Gubert, and Senne [2012], are operative, but we are not able to pin down such effects in our data.

Regarding mechanism (iii), the Spanish Migrant Survey asked individuals how they send remittances, offering the following answers: (a)Bank transfer, (b)money order in post office, (c)agency, (d)with other people, (e)different way. Table A2 of the Appendix displays the summary statistics for these variables. More than half of all individuals send remittances via agencies, followed by bank transfers (29\%), and money orders in post offices (14\%). Around 4\% send remittances with other people. For approximately a third of individuals in our sample who answered this question we construct two dummy variables. The first one takes on value one for those who use bank transfers and zero otherwise, and the second dummy variable takes on value one for individuals who indicate the use of other 
formal channels (money order in post office or agency). For this subsample of individuals who provided information on remittance channels, we repeat our IV estimation replacing the previous outcome variable by these indicator variables. Table 4.5 displays the results. We find that due to network effects migrants are more likely to send remittances via bank transfers and are less likely to use other formal means such as money orders in post offices or agencies.

Table 4.5: Mechanism of network effects: Use of different remittance channels

\begin{tabular}{lcc} 
& Bank transfer & Other formal channels \\
\cline { 2 - 3 } Network effects & $(1)$ & $(2)$ \\
Presence & 0.0001 & -.0001 \\
& $(0.00005)^{*}$ & $(0.00005)^{*}$ \\
Obs. & -.011 & 0.011 \\
$R^{2}$ & $(0.03)$ & $(0.03)$ \\
\hline \hline
\end{tabular}

Dependent variables in column (1) and (2) respectively are dummy variable indicating if individuals send remittances by bank transfer or other formal channels (money order in post office or agencies). The coefficients are marked with $*$ if the level of significance is between $5 \%$ and $10 \%, * *$ if the level of significance is between $1 \%$ and $5 \%$ and *** if the level of significance is less than 1\%. All regressions are estimated by population-weighted 2SLS and contain all individual characteristics included in our main estimation (see Table A4) as well as municipality and country dummies. Standard errors are clustered at the municipality-country level.

In order to further investigate how such a change in remittance channels provoked by network effects might lead to higher remittances, we consider data from the World Bank on providers in Spain for sending remittances. Data is available for the following ten countries which receive particularly large amounts of remittances from Spain: Brazil, Bulgaria, China, Colombia, Dominican Republic, Ecuador, Morocco, Peru, Philippines, and Romania. Note that individuals from these ten countries represent $47 \%$ of all individuals in our sample and more than 2.2 out of the 5 million immigrants residing in Spain. Table A3 in the Appendix displays the names of the most and least expensive providers, their type (agency, bank, post) and costs charged (in \%) for sending $200 \$$ and $500 \$$ respectively, for the earliest available data in 2008.

For individuals from these ten countries who answered the survey question on remittance channels, we construct dummy variables indicating if they have used their country's most expensive channel. With this indicator as the outcome variable, we reestimate our regression for mechanisms of network effects. Results are displayed in Table 4.6. Network effects are related to fewer individuals using the most expensive channel for sending money to their country of origin. While effects are rather small, they suggest a possible channel by which network effects could lead to higher remittances. If large networks of migrants 
from countries that remit a lot are better at sharing information about the cheapest ways of sending money home, then cost savings in fees could allow them to send more money over the course of a year.

Table 4.6: Mechanism of network effects: Use of most expensive remittance channels (sample of individuals from 10 countries of origin)

\begin{tabular}{lcc} 
& for sending $500 \$$ & for sending $200 \$$ \\
\cline { 2 - 3 } & $(1)$ & $(2)$ \\
\hline Network effects & -.0009 & -.0009 \\
Presence & $(0.0004)^{* *}$ & $(0.0004)^{* *}$ \\
& 0.381 & 0.462 \\
Obs. & $(0.193)^{* *}$ & $(0.208)^{* *}$ \\
$R^{2}$ & 2,955 & 2,955 \\
\hline \hline
\end{tabular}

Dependent variables in column (1) and (2) respectively are dummy variable indicating if individuals send remittances by using the most expensive remittance mode for their country (based on information from World Bank Data). The sample for these regressions is limited to individuals from Brazil, Bulgaria, China, Colombia, Dominican Republic, Ecuador, Morocco, Peru, Philippines, and Romania. The coefficients are marked with * if the level of significance is between $5 \%$ and $10 \%$, $* *$ if the level of significance is between $1 \%$ and $5 \%$ and $* * *$ if the level of significance is less than $1 \%$. All regressions are estimated by population-weighted 2SLS and contain all individual characteristics included in our main estimation (see Table A4) as well as municipality and country dummies. Standard errors are clustered at the municipality-country level.

\subsection{Macroeconomic implications of network effects}

The spread - i.e. the percentage point difference in costs between most and least expensive providers- varies quite a bit across the sample of ten countries. A lower spread could be interpreted as an indicator of increased competition among providers. Looking at the average measure of network effects by country and cost spreads for sending $200 \$$ and $500 \$$, we find cross-country correlations of -0.0601 and -0.4892 respectively (both correlations are significant at the $1 \%$ level.) Cost differences between providers are hence lower for countries characterized by stronger network effects in Spain. Or put otherwise, individuals from countries that send a lot of remittances and who tend to geographically concentrate more, face lower spreads. If migrant networks are able to better share information about costs effective ways of sending remittances to their countries of origin, then network effects could potentially affect spreads. In the spirit of findings on the effect of migrant networks on trade flows, this could be interpreted as evidence for the existence of additional macroeconomic effects of migrant networks. 


\section{Conclusion}

Immigrant networks have causal effects on individuals' remittance sending behavior. In particular, migrants from above-average remitting countries send more remittances when they live surrounded by relatively more co-nationals. Our results suggests that these network effects are due to improved information sharing regarding cost effective ways of sending money home. Network effects hence have the power to boost policy efforts to reduce remittance costs, such as the World Bank's "Project Greenback."

Remittances to developing countries have been shown to have powerful effects on individual outcomes such as education and entrepreneurship (Yang [2008]) as well as countries' development; e.g. capital accumulation (Chiodi, Jaimovich, and Montes-Rojas [2012] ) or poverty reduction (Yang and Martinez [2005]). Our results highlight that migrant networks could play important role for increasing remittances, and that positive network effects for remittances are particularly strong for individuals whose children and spouse remain in the country of origin. Furthermore, large networks of individuals who send a lot of remittances might be able to exert sufficient market pressure to affect the costs of sending remittances. Relatively small network effects could thus translate into higher remittances which have important effects for individuals in receiving countries.

\section{References}

Amuedo-Dorantes, Catalina and Susan Pozo (2006): "Remittances and Insurance: Evidence from Mexican Migrants," Journal of Public Economics, 19(2), pp. $227-254$.

Andersson, Fredrik; Burgess, Simon and Julia Lane (2014): "Do as the Neighbors Do: Examining the Effect of Residential Neighborhoods on Labor Market Outcomes," Journal of Labor Research, 35(4), pp. 373-392.

Åslund, Olof and Peter Fredriksson (2009): "Peer Effects in Welfare Dependence: Quasi-Experimental Evidence," Journal of Human Resources, 44(3), pp. 798825 .

Beaman, Lori A. (2012): "Social Networks and the Dynamics of Labor Market Outcomes: Evidence from Refugees Resettled in the U.S," Review of Economic Studies, 79(1), pp. 128-161. 
Bertrand, Marianne; Luttmer, Erzo F. P. and Sendhil Mullainathan (2000): "Network Effects and Welfare Cultures," Quarterly Journal of Economics, 115(3), pp. 1019-1055.

Borjas, George J. (1998): "To Ghetto or Not to Ghetto: Ethnicity and Residential Segregation," Journal of Urban Economics, 44, pp. 228-253.

Borjas, George J. (1995): "Ethnicity, Neighborhoods, and Human-Capital Externalities," American Economic Review, 85(3), pp. 365-390.

Chiodi, Vera; Jaimovich, Esteban and Gabriel Montes-Rojas (2012): "Migration, Remittances and Capital Accumulation: Evidence from Rural Mexico," Journal of Development Studies, 48(8), pp.1139-1155.

Chort, Isabelle; Gubert, Flore and Jean-Noel Senne (2012): "Migrant Networks as a Basis for Social Control: Remittance Incentives among Senegalese in France and Italy," Regional Science and Urban Economics, 42(5), pp. 858-874.

Clarke, George R.G. and Scott J. Wallsten (2003): "Do Remittances Act Like Insurance? Evidence From a Natural Disaster in Jamaica," mimeo.

Damm, Anna Piil (2009): "Ethnic Enclaves and Immigrant Labor Market Outcomes: Quasi-Experimental Evidence," Journal of Labor Economics, 27(2), pp. 281314.

Dustmann, Christian and Josep Mestres (2010): "Remittances and temporary migration," Journal of Development Economics, 92, pp. 62-70.

Funkhouser, Edward (1995): "Remittances from International Migration: A Comparison of El Salvador and Nicaragua," Review of Economics and Statistics, 77(1), pp. 137-146.

Gonzalez, Libertad and Francesc Ortega (2012): "Immigration and Housing Boom: Evidence from Spain," Journal of Regional Science, 0(0), pp.1-23.

Herander, Mark G. and Luz A. Saavedra (2005): "Exports and the structure of immigrant-based networks: the role of geographic proximity," Review of Economics and Statistics, 87(2), pp. 323-335.

Joseph, Thomas; Nyarko, Yaw and Shing-Yi Wang (2015): "Asymmetric Information and Remittances: Evidence from Matched Administrative Data," NBER Working Paper No. 20986. 
Lucas, Robert E. B. and Oded Stark (1985): "Motivations to Remit: Evidence from Botswana," Journal of Political Economy, 93(5), pp. 901-918

Maggard, Kasey Q. (2004): "The role of social capital in the remittance decisions of Mexican migrants from 1969 to 2000," Working Paper No. 2004-29, Federal Reserve Bank of Atlanta.

Manski, Charles F (1993): "Identification of Endogenous Social Effects: The Reflection Problem," Review of Economic Studies, 60(3), pp. 531-42.

Merkle, Lucie and Klaus F. Zimmermann (1992): "Savings, remittances, and return migration," Economic Letters, 38, pp. 77-81.

Spanish Ministry of Internal Affairs (2007): "Balance de la lucha contra la inmigración ilegal 2007," Ministerio del Interior.

Mohapatra, Sanket; Joseph, George and Dilip Ratha (2009): "Remittances and Natural Disasters Ex-post Response and Contribution to Ex-ante Preparedness," World Bank Policy Research Working Paper 4972.

Munshi, Kaivan (2003): "Networks in The Modern Economy: Mexican Migrants in the U.S. Labor Market," Quarterly Journal of Economics, 118(2), pp. 549-599.

Patel, Krishna and Francis Vella (2013): "Immigrant Networks and Their Implications for Occupational Choice and Wages," Review of Economics and Statistics, 118(2), pp. 549-599.

Peri, Giovanni and Francisco Requena-Silvente (2010): "The trade creation effect of immigrants: evidence from the remarkable case of Spain," Canadian Journal of Economics, 10, pp. 1433-1459.

Rapoport, Hillel and Frédéric Docquier (2006): "The Economics of Migrants' Remittances," in Handbook of the Economics of Giving, Altruism and Reciprocity, Volume II, edited by Serge-Christophe Kolm and Jean Mercier Ythier, North Holland, Amsterdam.

Reher, David and Miguel Requena (2009): "The National Immigrant Survey of Spain. A New Data Source for Migration Studies in Europe," Demographic Research, 20(12), pp. 253-278.

Sinning, Mathias G. (2011): "Determinants of Savings and Remittances: Empirical Evidence from Immigrants to Germany," Review of Economics of the Household, $9(1)$, pp. 45-67. 
World Bank (2015): Migration and Remittance Data.

Yang, Dean (2008): "International Migration, Remittances, and Household Investment: Evidence from Philippine Migrants' Exchange Rate Shocks," Economic Journal, 118(528) pp. 591-630.

Yang, Dean and HwaJung Choi (2007): "Are Remittances Insurance? Evidence from Rainfall Shocks in the Philippines," World Bank Economic Review, 21(2), pp. $219-248$.

Yang, Dean and Claudia Martinez (2005): "Remittances and Poverty in Migrants' Home Areas: Evidence from the Philippines," in International Migration, Remittances, and the Brain Drain, edited by Fréderic Docquier et al. Worldbank, Washington. 


\section{A Appendix}

Figure A-1: Foreign population in Spain and remittance outflows

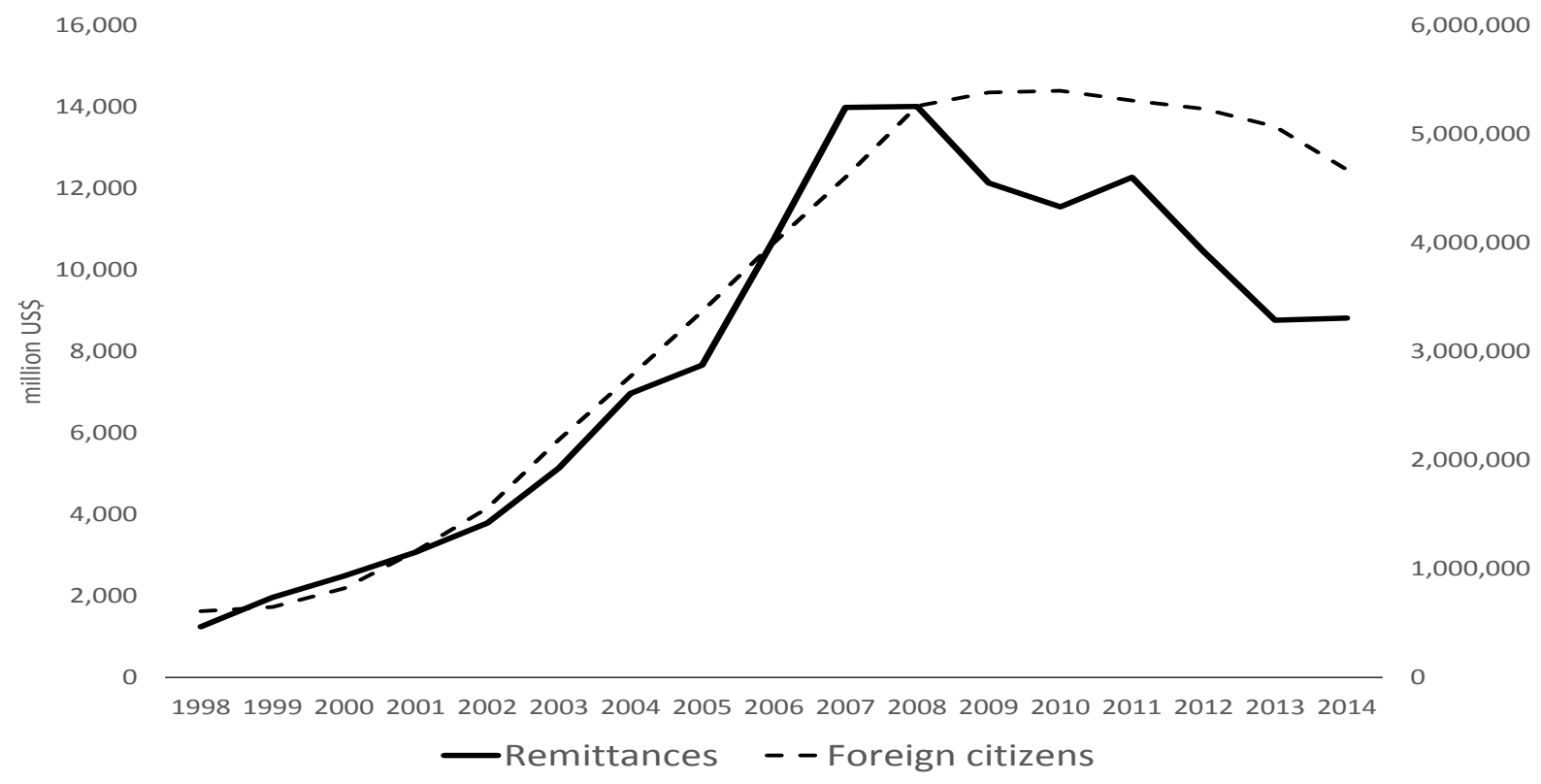

Data: World Bank for remittances and Eurostat

Figure A-2: Representativeness of foreign-born individuals in Spain by autonomous region (left) and province (right), 2007

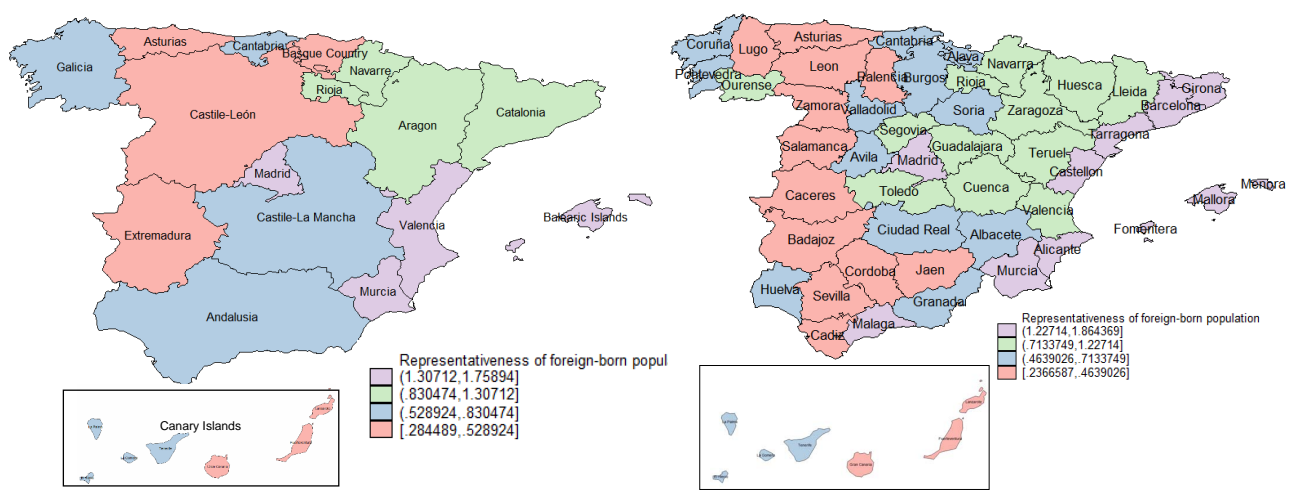

Data: Spanish National Statistics Institute (INE) 


\section{Table A1: Population-weighted averages for key variables by country of origin}

\begin{tabular}{|c|c|c|c|c|c|c|}
\hline Country & Individuals (survey) & Individuals Spain & Age & Quantity remitted & Close family abroad & Monthly labor income \\
\hline Morocco & 1,375 & 605,961 & 38.1 & 506.05 & 0.112 & 569.24 \\
\hline Romania & 1,075 & 397,270 & 32.2 & 895.74 & 0.099 & 727.10 \\
\hline Ecuador & 1,052 & 456,641 & 33.3 & 1554.24 & 0.197 & 741.47 \\
\hline France & 914 & 199,364 & 44.0 & 111.40 & 0.043 & 888.08 \\
\hline Colombia & 837 & 286,969 & 36.9 & 1444.37 & 0.187 & 739.46 \\
\hline United Kingdom & 728 & 283,667 & 53.8 & 96.20 & 0.408 & 441.61 \\
\hline Argentina & 721 & 271,444 & 41.1 & 288.01 & 0.072 & 866.71 \\
\hline Germany & 596 & 208,933 & 45.3 & 25.68 & 0.151 & 774.62 \\
\hline Portugal & 469 & 93,767 & 44.8 & 534.81 & 0.107 & 540.60 \\
\hline Bolivia & 371 & 140,740 & 31.3 & 1453.86 & 0.242 & 670.23 \\
\hline Peru & 345 & 123,464 & 39.2 & 1215.15 & 0.166 & 916.46 \\
\hline Brazil & 281 & 93,396 & 34.1 & 574.69 & 0.088 & 643.77 \\
\hline Cuba & 277 & 79,228 & 51.2 & 407.71 & 0.120 & 576.82 \\
\hline Bulgaria & 277 & 100,763 & 35.8 & 766.53 & 0.135 & 690.24 \\
\hline Uruguay & 238 & 76,635 & 39.4 & 212.86 & 0.066 & 779.98 \\
\hline Switzerland & 206 & 62,632 & 40.8 & 0 & 0.101 & 623.17 \\
\hline Dominican Republic & 204 & 87,111 & 36.3 & 927.62 & 0.229 & 618.54 \\
\hline Italy & 183 & 60,175 & 46.7 & 157.38 & 0.145 & 741.58 \\
\hline Ukraine & 174 & 69,359 & 37.5 & 1203.03 & 0.222 & 774.00 \\
\hline Algeria & 171 & 52,159 & 40.2 & 324.97 & 0.126 & 511.68 \\
\hline Belgium & 133 & 42,469 & 49.9 & 16.20 & 0.240 & 525.17 \\
\hline Poland & 132 & 44,339 & 35.8 & 727.81 & 0.150 & 822.40 \\
\hline Russia & 118 & 47,515 & 38.1 & 342.83 & 0.100 & 540.54 \\
\hline USA & 101 & 32,626 & 42.6 & 20.60 & 0.069 & 1074.87 \\
\hline Netherlands & 94 & 42,146 & 48.1 & 13.46 & 0.196 & 530.04 \\
\hline China & 88 & 104,789 & 34.0 & 1248.45 & 0.034 & 691.58 \\
\hline Paraguay & 83 & 30,155 & 32.2 & 1621.56 & 0.198 & 724.53 \\
\hline Philippines & 78 & 26,368 & 43.4 & 1262.55 & 0.218 & 808.80 \\
\hline Pakistan & 62 & 43,025 & 34.7 & 688.11 & 0.319 & 733.43 \\
\hline Equatorial Guinea & 60 & 19,456 & 39.4 & 153.33 & 0.149 & 612.62 \\
\hline Moldavia & 43 & 11,034 & 30.7 & 1007.87 & 0.113 & 862.98 \\
\hline Nigeria & 43 & 29,802 & 30.6 & 1336.81 & 0.169 & 550.50 \\
\hline Senegal & 39 & 34,070 & 37.1 & 1067.78 & 0.539 & 462.88 \\
\hline Sweden & 38 & 17,738 & 54.5 & 31.02 & 0.279 & 379.68 \\
\hline Denmark & 33 & 9,975 & 53.9 & 7.56 & 0.153 & 445.10 \\
\hline Lithuania & 31 & 15,200 & 29.7 & 371.15 & 0.095 & 693.27 \\
\hline Ghana & 27 & 13,33 & 32.8 & 1285.57 & 0.509 & 810.49 \\
\hline Australia & 25 & 5,131 & 36.7 & 0 & 0 & 669.72 \\
\hline India & 24 & 23,296 & 39.7 & 172.16 & 0.007 & 874.50 \\
\hline Austria & 24 & 7,704 & 48.4 & 0 & 0 & 990.70 \\
\hline Norway & 23 & 14,037 & 47.8 & 85.35 & 0.392 & 531.32 \\
\hline Armenia & 20 & 9,186 & 34.5 & 611.13 & 0.038 & 546.66 \\
\hline Czech Republic & 19 & 5,654 & 38.8 & 94.71 & 0.210 & 424.12 \\
\hline Georgia & 16 & 6,321 & 37.6 & 712.03 & 0.351 & 580.73 \\
\hline Canada & 15 & 5,420 & 44.4 & 0 & 0 & 934.44 \\
\hline Guinea & 15 & 9,901 & 34.5 & 547.03 & 0.191 & 625.59 \\
\hline El Salvador & 14 & 5,102 & 47.7 & 68.56 & 0.271 & 580.67 \\
\hline Finland & 13 & 9,865 & 60.5 & 0 & 0.456 & 113.47 \\
\hline Honduras & 12 & 10,652 & 31.1 & 326.66 & 0.058 & 775.79 \\
\hline Japan & 11 & 5,684 & 32.7 & 0 & 0 & 532.04 \\
\hline Bangladesh & 7 & 6,130 & 29.9 & 623.70 & 0.299 & 528.89 \\
\hline Mauritania & 6 & 9,308 & 38.2 & 2904.42 & 0.517 & 835.66 \\
\hline Guinea Bissau & 4 & 5,274 & 37.3 & 2350.50 & 0.130 & 1009.79 \\
\hline
\end{tabular}


Table A2: Additional summary statistics (population-weighted)

\begin{tabular}{|c|c|c|c|c|c|}
\hline Variable & Mean & Std. Dev. & Min. & Max. & $\mathbf{N}$ \\
\hline \multicolumn{6}{|l|}{ Heterogeneity of network effects } \\
\hline Spanish nationality & 0.233 & 0.423 & 0 & 1 & 12,633 \\
\hline Years in Spain & 11.495 & 12.924 & 0 & 90 & 12,487 \\
\hline $\begin{array}{l}\text { Close family (spouse or children) abroad } \\
\text { Continent of origin }\end{array}$ & 0.157 & 0.364 & 0 & 1 & 12,656 \\
\hline$\overline{\text { Europe }}$ & 0.405 & 0.491 & 0 & 1 & 12,656 \\
\hline Africa & 0.152 & 0.359 & 0 & 1 & 12,656 \\
\hline America & 0.406 & 0.491 & 0 & 1 & 12,656 \\
\hline Asia & 0.035 & 0.185 & 0 & 1 & 12,656 \\
\hline Oceania & 0.002 & 0.043 & 0 & 1 & 12,656 \\
\hline \multicolumn{6}{|l|}{ Mechanisms of network effects } \\
\hline $\begin{array}{l}\text { Homeowner abroad } \\
\text { Remittance Channel }\end{array}$ & 0.325 & 0.468 & 0 & 1 & 12,656 \\
\hline Post office & 0.139 & 0.346 & 0 & 1 & 4,170 \\
\hline Bank transfer & 0.287 & 0.452 & 0 & 1 & 4,170 \\
\hline Agencies & 0.521 & 0.5 & 0 & 1 & 4,170 \\
\hline Other people & 0.042 & 0.202 & 0 & 1 & 4,170 \\
\hline Other method & 0.011 & 0.105 & 0 & 1 & 4,170 \\
\hline \multicolumn{6}{|l|}{ Missing observations on: } \\
\hline Education & 0.084 & 0.277 & 0 & 1 & 12,656 \\
\hline Educated in Spain & 0.084 & 0.277 & 0 & 1 & 12,656 \\
\hline Siblings abroad & 0.237 & 0.425 & 0 & 1 & 12,656 \\
\hline Children abroad & 0.457 & 0.498 & 0 & 1 & 12,656 \\
\hline Father abroad & 0.073 & 0.261 & 0 & 1 & 12,656 \\
\hline Mother abroad & 0.103 & 0.305 & 0 & 1 & 12,656 \\
\hline Income & 0.002 & 0.042 & 0 & 1 & 12,656 \\
\hline
\end{tabular}

Table A3: Remittance prices charged by cheapest and most expensive providers for sending 200\$ and 500\$ from Spain (in\%), 2008 (2nd Q)

\begin{tabular}{|c|c|c|c|c|c|c|}
\hline & \multicolumn{3}{|c|}{ Cheapest provider } & \multicolumn{3}{|c|}{ Most expensive provider } \\
\hline & Provider & Туре & Cost & Provider & Туре & Cost \\
\hline \multicolumn{7}{|l|}{ Sending $200 \$$} \\
\hline Brazil & Trans-Fast & Agency & 0.53 & Ria & Agency & 6.25 \\
\hline Bulgaria & Maccorp Exact Exchange & Agency & 4.44 & Western Union & Agency/Post & 10.74 \\
\hline China & Money Exchange & Agency & 11.64 & Western Union & Agency/Post & 18.33 \\
\hline Colombia & Latinoenvios & Bank & 3.48 & Western Union & Agency/Post & 9.58 \\
\hline Dominican Republic & Santander & Bank & 4.59 & Western Union & Agency/Post & 7.80 \\
\hline Ecuador & Latinoenvios & Bank & 3.95 & Caja Madrid & Bank & 12.05 \\
\hline Morocco & Ria & Agency & 3.71 & La Caixa & Bank & 14.19 \\
\hline Peru & Latinoenvios & Bank & 3.62 & Caja Madrid & Bank & 12.05 \\
\hline Philippines & Ria & Agency & 4.66 & MoneyGram & Agency & 15.99 \\
\hline Romania & Master Envios & Agency & 4.44 & Safe Money Transfer & Agency & 9.63 \\
\hline \multicolumn{7}{|l|}{ Sending $500 \$$} \\
\hline Brazil & Trans-Fast & Agency & 1.22 & Ria & Agency & 3.62 \\
\hline Bulgaria & Maccorp Exact Exchange & Agency & 1.82 & Western Union & Agency/Post & 8.94 \\
\hline China & Money Exchange & Agency & 5.08 & Western Union & Agency/Post & 9.3 \\
\hline Colombia & Latinoenvios & Bank & 2.16 & MoneyGram & Agency & 8.74 \\
\hline Dominican Republic & Universal de Envios & Agency & 3.03 & Western Union & Agency/Post & 5.4 \\
\hline Ecuador & BBVA Dinero Express & Bank & 2.29 & Caja Madrid & Bank & 8.11 \\
\hline Morocco & Ria & Agency & 1.08 & La Caixa & Bank & 13.31 \\
\hline Peru & BBVA Dinero Express & Bank & 2.29 & Caja Madrid & Bank & 8.11 \\
\hline Philippines & Ria & Agency & 2.04 & MoneyGram & Agency & 14.27 \\
\hline Romania & Master Envios Unidos & Agency & 1.82 & Western Union & Agency/Post & 9.7 \\
\hline
\end{tabular}

Source: World Bank Remittance Prices. Note that since 1999 Western Union signed an agreement with the Spanish postal service such that money orders can be send from all post offices. Latinoenvios is part of Santander Bank. 


\section{Table A4: Main estimation: Full results}

\begin{tabular}{|c|c|c|c|c|c|}
\hline \multirow{2}{*}{$\overline{\text { Mean remit, mun. and country }}$} & & & & & \\
\hline & $\frac{(1)}{0.972}$ & $(2)$ & (3) & (4) & (5) \\
\hline Mean remit, country & & $\begin{array}{l}0.709 \\
(0.322)^{* *}\end{array}$ & & & \\
\hline Mean remit, municipality & & & $\begin{array}{l}0.493 \\
(0.203)^{* *}\end{array}$ & & \\
\hline Network effects & & & & $\begin{array}{l}0.051 \\
(0.035)\end{array}$ & $\begin{array}{l}0.609 \\
(0.242)^{* *}\end{array}$ \\
\hline Representativeness & & & & $\begin{array}{l}4.990 \\
(21.755)\end{array}$ & $\begin{array}{l}-56.967 \\
(95.136)\end{array}$ \\
\hline Male & $\begin{array}{l}84.165 \\
(32.888)^{* *}\end{array}$ & $\begin{array}{l}117.555_{* *} \\
(38.390)^{* * *}\end{array}$ & $\begin{array}{l}117.5555_{* *} \\
(38.390)^{* * *}\end{array}$ & $\begin{array}{l}116.376 \\
(38.448)^{* * *}\end{array}$ & $\begin{array}{l}104.952 \\
(39.326)^{* * *}\end{array}$ \\
\hline Age & $\begin{array}{l}13.256 \\
(6.016)^{* *}\end{array}$ & $(6.940)^{*}$ & $(6.940)^{*}$ & $(6.937)^{*}$ & $(6.998)^{*}$ \\
\hline Age squared & $(0.053)^{* *}$ & $(0.063)^{* *}$ & $(0.063)^{* * *}$ & $(0.063)^{* *}$ & $(0.064)^{*}$ \\
\hline Primary education & $\begin{array}{l}51.546 \\
(61.550)\end{array}$ & $\begin{array}{c}93.411 \\
(111.707)\end{array}$ & $\begin{array}{c}93.411 \\
(111.707)\end{array}$ & $\begin{array}{c}93.074 \\
(111.599)\end{array}$ & $\begin{array}{c}83.508 \\
(113.480)\end{array}$ \\
\hline Secondary education & $\begin{array}{l}118.743 \\
(56.991)^{* *}\end{array}$ & $\begin{array}{l}128.184 \\
(104.450)\end{array}$ & $\begin{array}{l}128.184 \\
(104.450)\end{array}$ & $\begin{array}{l}127.180 \\
(104.583)\end{array}$ & $\begin{array}{l}101.889 \\
(108.191)\end{array}$ \\
\hline Tertiary education & $\begin{array}{l}36.353 \\
(61.567)\end{array}$ & $\begin{array}{c}33.610 \\
(108.136)\end{array}$ & $\begin{array}{l}33.610 \\
(108.136)\end{array}$ & $\begin{array}{l}32.552 \\
(108.085)\end{array}$ & $\begin{array}{l}-7.585 \\
(114.170)\end{array}$ \\
\hline Educated in Spain & $\begin{array}{l}-30.060 \\
(34.046)\end{array}$ & $(44.411)^{-92.876}$ & $(44.411)^{-92.876}$ & $(44.591)^{-9 *}$ & $(51.505)^{* *}$ \\
\hline Married & $\begin{array}{l}-14.634 \\
(34.308)\end{array}$ & $\begin{array}{l}-26.559 \\
(41.171)\end{array}$ & $\left(\begin{array}{l}-26.559 \\
(41.171)\end{array}\right.$ & $\begin{array}{l}-26.222 \\
(41.200)\end{array}$ & $\begin{array}{l}-26.844 \\
(42.068)\end{array}$ \\
\hline Number household members & $\begin{array}{l}-12.260 \\
(13.285)\end{array}$ & $\begin{array}{l}-10.337 \\
(15.390)\end{array}$ & $\begin{array}{l}-10.337 \\
(15.390)\end{array}$ & $\begin{array}{l}-10.802 \\
(15.489)\end{array}$ & $\begin{array}{l}-12.904 \\
(15.803)\end{array}$ \\
\hline Spouse abroad & $\begin{array}{l}710.175 \\
(188.882)^{* * *}\end{array}$ & $\begin{array}{l}949.136 \\
(208.066)^{* * *}\end{array}$ & $\begin{array}{l}949.136 \\
(208.066)^{* * *}\end{array}$ & $\begin{array}{l}945.673 \\
(207.993)^{* * *}\end{array}$ & $\begin{array}{l}912.819 \\
(211.235)^{* * *}\end{array}$ \\
\hline Sibling abroad & $\left(\begin{array}{l}14.595 \\
(40.885)\end{array}\right.$ & $\left(\begin{array}{l}7.376 \\
48.801)\end{array}\right.$ & $\begin{array}{l}7.376 \\
(48.801)\end{array}$ & $\begin{array}{c}6.529 \\
(48.735)\end{array}$ & $\left(\begin{array}{l}-7.669 \\
(48.676)\end{array}\right.$ \\
\hline Children abroad & $\begin{array}{l}479.081 \\
(79.858)^{* * *}\end{array}$ & $\begin{array}{l}713.467 \\
(88.148)^{* * *}\end{array}$ & $\begin{array}{l}713.467 \\
(88.148)^{* * *}\end{array}$ & $\begin{array}{l}717.700 \\
(88.218)^{* * * *}\end{array}$ & $\begin{array}{l}781.109 \\
(93.608)^{* * *}\end{array}$ \\
\hline Father abroad & $\begin{array}{l}142.994 * * \\
(49.399)^{* * *}\end{array}$ & $(60.844)^{* * *}$ & $(60.844)^{* * *}$ & $(60.717)^{19 * *}$ & $\begin{array}{l}183.041 \\
(60.685)^{* * *}\end{array}$ \\
\hline Mother abroad & $\begin{array}{l}140.871 \\
(48.591)^{* * *}\end{array}$ & $(57.006)^{* * *}$ & $(57.006)^{237 * 18 *}$ & $(56.936)^{* * *}$ & $(57.334)^{* * *}$ \\
\hline Return intentions & $\begin{array}{l}270.696 \\
(102.602)^{* * *}\end{array}$ & $\begin{array}{l}270.002^{2 *} \\
(111.700)^{* *}\end{array}$ & $\begin{array}{l}270.002^{* *} \\
(111.700)^{* *}\end{array}$ & $\begin{array}{l}266.768 \\
(111.537)^{* *}\end{array}$ & $\begin{array}{l}240.629 \\
(113.848)^{* *}\end{array}$ \\
\hline Participation in elections & $\begin{array}{c}31.469 \\
(37.686)\end{array}$ & $\begin{array}{l}62.233 \\
(57.870)\end{array}$ & $\begin{array}{l}62.233 \\
(57.870)\end{array}$ & $\begin{array}{l}56.418 \\
(58.055)\end{array}$ & $\begin{array}{l}-21.277 \\
(60.283)\end{array}$ \\
\hline Intentions to bring family & $\begin{array}{c}315.776 \\
(65.346)^{* * *}\end{array}$ & $\begin{array}{c}503.796 \\
(68.083)^{* * *}\end{array}$ & $\begin{array}{c}503.796 \\
(68.083)^{* * *}\end{array}$ & $\begin{array}{c}502.813 \\
(68.123)^{* * *}\end{array}$ & $\begin{array}{l}494.921 \\
(69.348)^{* * *}\end{array}$ \\
\hline Employed & $\begin{array}{l}102.386 \\
(48.561)^{* *}\end{array}$ & $\begin{array}{l}204.812 * * \\
(53.034)^{* * *}\end{array}$ & $\begin{array}{l}204.812 * * \\
(53.034)^{* * *}\end{array}$ & $\begin{array}{l}202.307 * * \\
(53.440)^{* * *}\end{array}$ & $\begin{array}{l}178.642 \\
(54.117)^{* * *}\end{array}$ \\
\hline Income & $\begin{array}{c}0.069 \\
(0.025)^{* * *}\end{array}$ & $\begin{array}{c}0.085 \\
(0.034)^{* *}\end{array}$ & $(0.034)^{* *}$ & $\begin{array}{c}0.086 \\
(0.034)^{* *}\end{array}$ & $\begin{array}{c}0.086 \\
(0.035)^{* *}\end{array}$ \\
\hline Municipality fixed effects & $\mathrm{x}$ & $\mathrm{x}$ & $\mathrm{x}$ & $\mathrm{x}$ & $\mathrm{x}$ \\
\hline $\begin{array}{l}\text { Country fixed effects } \\
\text { Obs. }\end{array}$ & $\begin{array}{c}\mathrm{x} \\
12,656\end{array}$ & 12,656 & $\begin{array}{c}x \\
12,656\end{array}$ & $\begin{array}{c}x \\
12,656\end{array}$ & $\begin{array}{c}\mathrm{x} \\
12,656\end{array}$ \\
\hline$R^{2}$ & 0.544 & 0.251 & 0.251 & 0.251 & 0.228 \\
\hline
\end{tabular}

The dependent variable is the amount of euros that individuals report to have remitted over the course of the previous year. The coefficients are marked with * if the level of significance is between $5 \%$ and $10 \%,{ }^{* *}$ if the level of significance is between $1 \%$ and $5 \%$ and $* * *$ if the level of significance is less than $1 \%$. Columns 1 to 4 are estimated by population-weighted OLS, column 5 is estimated using population-weighted 2SLS. Standard errors are clustered at the municipality-country level. 
Table A5: Network effects for individuals from above-average remitting countries in overrepresented municipalities

\begin{tabular}{lcc}
\hline Network effects & -.704 & -.312 \\
& $(0.62)$ & $(0.369)$ \\
Representativeness & -399.938 & -172.494 \\
& $(233.706)^{*}$ & $(340.129)$ \\
Network effects $\times$ above-average & 1.630 & \\
& $(0.841)^{*}$ & \\
Representativeness $\times$ above-average & 203.474 & 0.457 \\
& $(345.158)$ & $(0.432)$ \\
Network effects $\times$ overrepresented & & 380.135 \\
& & $(529.894)$ \\
Representativeness $\times$ overrepresented & & 12,656 \\
& & 0.247 \\
Obs. & 12,656 & 0.230 \\
$R^{2}$ & & \\
\hline \hline
\end{tabular}

The dependent variable is the amount of euros that individuals report to have remitted over the course of the previous year. The coefficients are marked with * if the level of significance is between $5 \%$ and $10 \%, * *$ if the level of significance is between $1 \%$ and $5 \%$ and $* * *$ if the level of significance is less than $1 \%$. All regressions are estimated by population-weighted 2SLS and contain the full set of individual characteristics (see Table A4) as well as country and municipality dummies. Standard errors are clustered at the municipality-country level.

Table A6: Removing Controls: First stage network effects

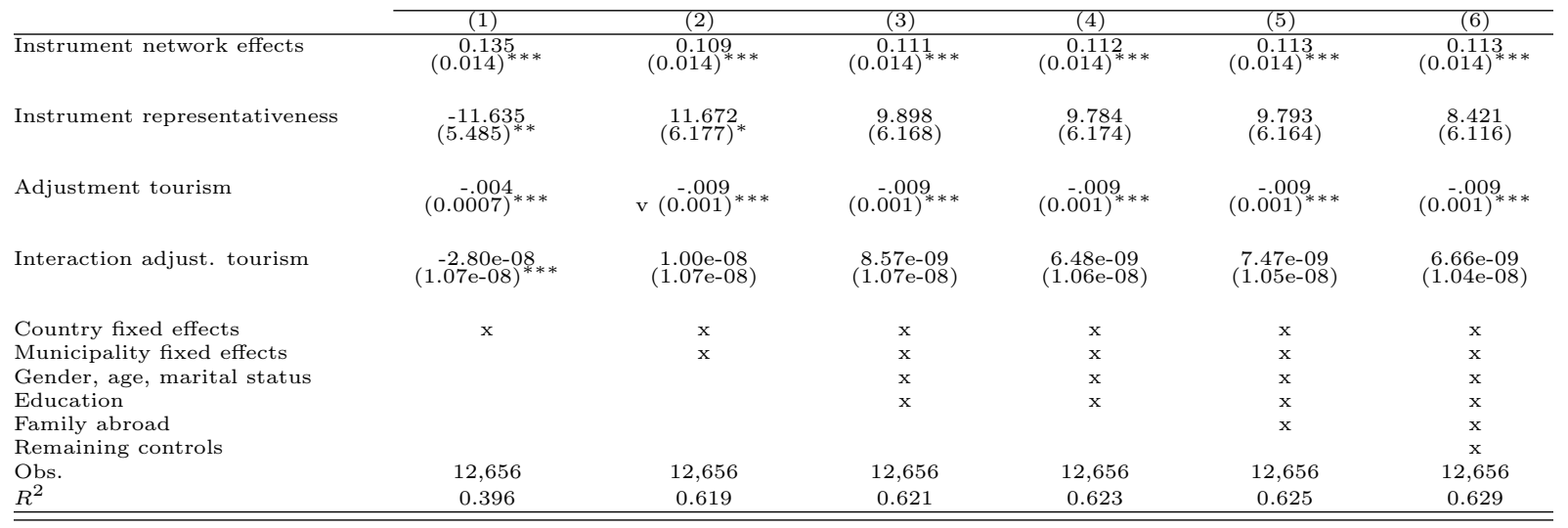

The dependent variable is "network effects" $\left(\overline{\overline{R_{k}}} \times \operatorname{Rep}_{j, k}\right)$. The coefficients are marked with * if the level of significance is between $5 \%$ and $10 \%, * *$ if the level of significance is between $1 \%$ and $5 \%$ and $* * *$ if the level of significance is less than $1 \%$. All regressions are estimated by population-weighted OLS. Standard errors are clustered at the municipality-country level. Remaining controls refer to number of household members, income, employment, return intentions, participation in elections, and intentions to bring family. 
Table A7: Removing Controls: First stage representativeness

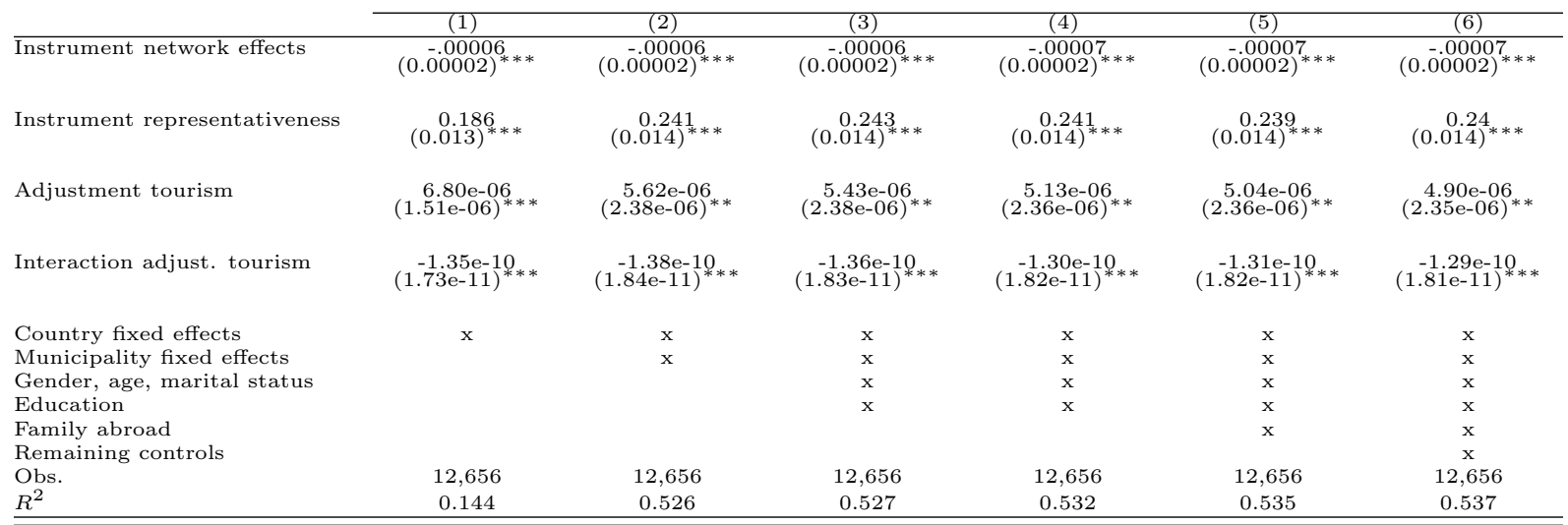

The dependent variable is "representativeness" $\left(\operatorname{Rep}_{j, k}\right)$. The coefficients are marked with * if the level of significance is between $5 \%$ and $10 \%,{ }^{* *}$ if the level of significance is between $1 \%$ and $5 \%$ and $* * *$ if the level of significance is less than 1\%. All regressions are estimated by population-weighted OLS. Standard errors are clustered at the municipality-country level. Remaining controls refer to number of household members, income, employment, return intentions, participation in elections, and intentions to bring family.

Table A8: Robustness Check: Different Samples

\begin{tabular}{lcccc} 
& Exclu. Morocco & Exclu.Romania & Exclu.Africa & Exlcu.islands \\
\cline { 2 - 5 } & $(1)$ & $(2)$ & $(3)$ & $(4)$ \\
\hline Network effects & 0.553 & 0.665 & 0.576 & 0.879 \\
& $(0.229)^{* *}$ & $(0.251)^{* * *}$ & $(0.247)^{* *}$ & $(0.343)^{* *}$ \\
Representativeness & -66.601 & 0.209 & -69.687 & -133.483 \\
& $(95.124)$ & $(111.843)$ & $(96.094)$ & $(133.851)$ \\
Obs. & 11,281 & 11,581 & 10,870 & 11,078 \\
$R^{2}$ & 0.239 & 0.235 & 0.238 & 0.203 \\
\hline \hline
\end{tabular}

The dependent variable is the amount of euros that individuals report to have remitted over the course of the previous year. The coefficients are marked with * if the level of significance is between $5 \%$ and $10 \%, * *$ if the level of significance is between $1 \%$ and $5 \%$ and $* * *$ if the level of significance is less than $1 \%$. All regressions are estimated by population-weighted 2 SLS and contain the full set of individual characteristics (see Table A4) as well as country and municipality dummies. Columns (1), (2), and (3) display results for samples that exclude individuals from Morocco, Romania, and Africa respectively. Column(4) shows results excluding immigrants living on the Balearic or Canary islands. Standard errors are clustered at the municipality-country level. 
Table A9: Robustness Check: Sample with minimum representation of 2,000 in Spain

\begin{tabular}{lccccc} 
& $(1)$ & $(2)$ & $(3)$ & $(4)$ & $(5)$ \\
\hline Mean remit, mun. and country & 0.973 & & & \\
Mean remit, country & $(0.017)^{* * *}$ & & & \\
& & 0.724 & & \\
Mean remit, municipality & & $(0.316)^{* *}$ & & \\
& & & 0.49 & & \\
Network effects & & $(0.204)^{* *}$ & & \\
& & & 0.061 & 0.669 \\
Representativeness & & & $(0.035)^{*}$ & $(0.276)^{* *}$ \\
& & & & 4.360 & -65.557 \\
Municipality fixed effects & $\mathrm{x}$ & $\mathrm{x}$ & & $(21.337)$ & $(95.329)$ \\
Country fixed effects & $\mathrm{x}$ & & $\mathrm{x}$ & $\mathrm{x}$ & $\mathrm{x}$ \\
Obs. & 12,835 & 12,835 & 12,835 & 12,835 & 12,835 \\
$R^{2}$ & 0.547 & 0.252 & 0.252 & 0.252 & 0.224 \\
\hline \hline
\end{tabular}

The dependent variable is the amount of euros that individuals report to have remitted over the course of the previous year. The coefficients are marked with * if the level of significance is between $5 \%$ and $10 \%,{ }^{*}$ if the level of significance is between $1 \%$ and $5 \%$ and $* * *$ if the level of significance is less than $1 \%$. Compared to our main sample here we also include individuals from countries with a minimum representation of 2,000-4,999 individuals. Columns 1 to 4 are estimated by population-weighted OLS, column 5 is estimated by population-weighted 2SLS. All regressions contain the full set of individual characteristics (see Table A4). Standard errors are clustered at the municipality-country level. 
Table A10: Robustness Check: Excluding countries whose GDP per capita in 2007 was larger than Spain's

\begin{tabular}{ccccc}
$(1)$ & $(2)$ & $(3)$ & $(4)$ & $(5)$ \\
\hline 0.952 & & & & \\
$0.019)^{* * *}$ & & & & \\
& 0.865 & & & \\
& $(0.328)^{* * *}$ & & & \\
& & 1.112 & & \\
& & $(0.061)^{* * *}$ & & \\
& & & 0.074 & 0.602 \\
& & & $(0.047)$ & $(0.244)^{* *}$ \\
& & & 9.165 & 53.196 \\
& & & $(27.979)$ & $(103.810)$ \\
$\mathrm{x}$ & $\mathrm{x}$ & & $\mathrm{x}$ & $\mathrm{x}$ \\
$\mathrm{x}$ & & $\mathrm{x}$ & $\mathrm{X}$ & $\mathrm{x}$ \\
9,497 & 9,497 & 9,497 & 9,497 & 9,497 \\
0.537 & 0.257 & 0.257 & 0.257 & 0.246 \\
\hline
\end{tabular}

The dependent variable is the amount of euros that individuals report to have remitted over the course of the previous year. The coefficients are marked with * if the level of significance is between $5 \%$ and $10 \%, * *$ if the level of significance is between $1 \%$ and $5 \%$ and $* * *$ if the level of significance is less than $1 \%$. Compared to our main sample here we exclude the following 17 countries who according to World Bank data had a GDP per capita in US\$ that was larger than Spain's: Australia, Austria, Belgium, Canada, Denmark, Finland, France, Germany, Ireland, Italy, Japan, Netherlands, Norway, Sweden, Switzerland, US, and UK. Columns 1 to 4 are estimated by population-weighted OLS, column 5 is estimated by population-weighted 2SLS. All regressions contain the full set of individual characteristics (see Table A4). Standard errors are clustered at the municipality-country level. 


\section{Table A11: Robustness Check: Alternative definition of network effects without logaithmic transformation of representativeness}

$(1)$

\begin{tabular}{lcc}
\hline Alternative network effects & 0.006 & 0.254 \\
& $(0.005)$ & $(0.114)^{* *}$ \\
Alternative representativeness & 2.276 & -46.871 \\
& $(2.303)$ & $(62.005)$ \\
Obs. & 12,656 & 12,656 \\
$R^{2}$ & 0.251 &. \\
\hline \hline
\end{tabular}

The dependent variable is the amount of euros that individuals report to have remitted over the course of the previous year. The coefficients are marked with * if the level of significance is between $5 \%$ and $10 \%, * *$ if the level of significance is between $1 \%$ and $5 \%$ and $* * *$ if the level of significance is less than $1 \%$. Compared to our main sample here we also include individuals from all countries of origin. "Alternative network effects" and "Alternative representativeness" are defined as $\left(\overline{\overline{R_{k}}} \times e^{R e p_{j, k}}\right)$ and $e^{R e p_{j, k}}$ respectively. Columns 1 is estimated by population-weighted OLS and column 2 by population-weighted 2SLS. All regressions contain the full set of individual characteristics (see Table A4). Standard errors are clustered at the municipality-country level.

Table A12: Testing for alternative mechanisms of network effects

\begin{tabular}{lcccccc} 
& employed & income & elections & return & house & bring family \\
\cline { 2 - 7 } & $(1)$ & $(2)$ & $(3)$ & $(4)$ & $(5)$ & $(6)$ \\
\hline Network effects & -.00006 & -.117 & 0.00002 & 0.00002 & $1.00 \mathrm{e}-05$ & $2.90 \mathrm{e}-06$ \\
\multirow{2}{*}{ Representativeness } & $(0.00006)$ & $(0.086)$ & $(0.00004)$ & $(0.00003)$ & $(0.00006)$ & $(0.00005)$ \\
& 0.035 & 73.513 & 0.006 & 0.029 & 0.03 & -.001 \\
Obs. & $(0.024)$ & $(40.291)^{*}$ & $(0.017)$ & $(0.012)^{* *}$ & $(0.022)$ & $(0.02)$ \\
$R^{2}$ & 12,656 & 12,656 & 12,656 & 12,656 & 12,656 & 12,656 \\
\hline \hline
\end{tabular}

The dependent variable is a dummy variable for employment (1), monthly income in euros (2), an indicator for participating in Spanish elections (3), a dummy variable for return intentions (4), an indicator for owning a house in the country of origin (5) and an indicator variable for intentions to bring family to Spain (6). The coefficients are marked with * if the level of significance is between $5 \%$ and $10 \%, * *$ if the level of significance is between $1 \%$ and $5 \%$ and $* * *$ if the level of significance is less than 1\%. All regressions contain the following controls: country and municipality dummies, gender, age marital status, education, time in Spain, number of household members, and family living abroad and they are estimated by population-weighted 2SLS. Standard errors are clustered at the municipality-country level. 